\title{
Cold acclimation triggers major transcriptional changes in Drosophila suzukii
}

\author{
Thomas Enriquez ${ }^{*}$ [D and Hervé Colinet
}

\begin{abstract}
Background: Insects have the capacity to adjust their physiological mechanisms during their lifetime to promote cold tolerance and cope with sublethal thermal conditions, a phenomenon referred to as thermal acclimation. The spotted wing drosophila, Drosophila suzukii, is an invasive fruit pest that, like many other species, enhances its thermotolerance in response to thermal acclimation. However, little is known about the underlying mechanisms of this plastic response. Here, we promoted flies' cold tolerance by gradually increasing acclimation duration (i.e. pre-exposure from $2 \mathrm{~h}$ to 9 days at $10^{\circ} \mathrm{C}$ ), and then compared transcriptomic responses of cold hardy versus cold susceptible phenotypes using RNA sequencing.

Results: Cold tolerance of $D$. suzukii increased with acclimation duration; the longer the acclimation, the higher the cold tolerance. Cold-tolerant flies that were acclimated for 9 days were selected for transcriptomic analyses. RNA sequencing revealed a total of 2908 differentially expressed genes: 1583 were up- and 1325 were downregulated in cold acclimated flies. Functional annotation revealed many enriched GO-terms among which ionic transport across membranes and signaling were highly represented in acclimated flies. Neuronal activity and carbohydrate metabolism were also enriched GO-terms in acclimated flies. Results also revealed many GO-terms related to oogenesis which were underrepresented in acclimated flies.

Conclusions: Involvement of a large cluster of genes related to ion transport in cold acclimated flies suggests adjustments in the capacity to maintain ion and water homeostasis. These processes are key mechanisms underlying cold tolerance in insects. Down regulation of genes related to oogenesis in cold acclimated females likely reflects that females were conditioned at $10^{\circ} \mathrm{C}$, a temperature that prevents oogenesis. Overall, these results help to understand the molecular underpinnings of cold tolerance acquisition in D. suzukii. These data are of importance considering that the invasive success of $D$. suzukii in diverse climatic regions relates to its high thermal plasticity.
\end{abstract}

Keywords: Thermal plasticity, Cold tolerance, Transcriptomics, Genes expression, Spotted wing drosophila

\section{Background}

The spotted wing drosophila, Drosophila suzukii, is a fruit fly originating from South-East Asia, invasive in Europe as well as North and South America [1] where it is continuously expending its repartition area $[2,3]$. Contrary to its relative species Drosophila melanogaster, which lays eggs exclusively on rotten fruits, D. suzukii females possess a serrated ovipositor that allows to break through fruit skin and lay eggs in fresh mature fruits [4].

\footnotetext{
* Correspondence: thomas.enriquez.tours@gmail.com Université de Rennes1, CNRS, ECOBIO - UMR 6553, 263 avenue du Général Leclerc, 35042 Rennes, France
}

After hatching, the larvae consume the fruits, causing damages that turn them uncommerciable $[5,6]$. Furthermore, wounds caused by female's ovipositor offer a way of entrance for pathogens, causing secondary infections [6]. This fly is highly polyphagous, targeting a broad range of cultivated fruit crops $[1,5,6]$, as well as wild hosts [7, 8]. Consequently, this pest has an important economic impact, especially for soft fruit production $[1$, $5,6]$. In order to facilitate the control of D. suzukii, knowledge about its biology is highly required, especially about its thermal physiology $[1,9,10]$. Thermal tolerance and especially the capacity of alien species to modulate their thermal tolerance thanks to phenotypic 
plasticity, is believed to be a key factor of their invasive success $[11,12]$. Therefore, increasing knowledge about thermal biology of D. suzukii is essential to predict evolution of its invasion front or its population dynamics in invaded areas and facilitate its control.

Like most insect species [13], D. suzukii is chill susceptible which means that it rapidly suffers chilling injuries at temperatures well above its freezing point [14-17]. In insects, chilling injuries result from complex physiological alterations such as loss of ion and water homeostasis which participate to the disruption of neuromuscular functions, leading to chill coma. Physiological injuries also compromise cell integrity, resulting in tissue damage, and in most extreme cases death [13, 18, 19]. To cope with these deleterious effects, insects can adjust their physiological state in anticipation of cold stress. Cold acclimation (triggered by pre-exposure to mild low temperature) is a typical example of phenotypical plasticity. Cold acclimation induces deep and complex physiological remodeling such as changes in composition of membranes [20], mobilization of cryoprotective metabolites [21-24], maintenance of metabolic homeostasis [25-28], altered stress genes expression $[29,30]$, and enhanced ability to maintain ion and water balance $[29,31,32]$. These changes prevent the development of chilling injuries, resulting in increased cold tolerance [13].

Drosophila suzukii displays a high plasticity of cold tolerance and responds to all forms of acclimation such as rapid cold hardening [33, 34], adult acclimation $[25,35,36]$ and developmental acclimation $[25,34,37,38]$. This fly is capable of surviving a three days exposure at $-7.5^{\circ} \mathrm{C}$ after dynamic acclimation (i.e. gradual cooling) [39]. Despite the economic importance of this species, the number of studies that focused on the underlying mechanisms of this plasticity remains scarce. Shearer et al., [37] explored transcriptional adjustments associated with the winter-phenotype generated by a combination of developmental and adult acclimation. This thermal treatment results in a cold tolerant winter phenotype showing a reproductive dormancy. In a previous work [25], we showed that flies subjected to both developmental and adult acclimation were characterized by the accumulation of cryoprotectants and were able to maintain metabolic homeostasis after cold stress, suggesting a deep biochemical remodeling linked to acclimation. So far, there is a limited understanding of the molecular mechanisms that underlie cold tolerance plasticity of $D$. suzukii.

In the present study, we subjected mature adults of $D$. suzukii to increasing acclimation periods (pretreatment from $2 \mathrm{~h}$ to 9 days at $10^{\circ} \mathrm{C}$ ) in order to investigate the cold pre-exposure period needed to reach high cold tolerance. Next, we identified the molecular correlates underlying cold tolerance acquisition in D. suzukii using the hypothesis-generating and explorative power of RNA sequencing (RNAseq). We expected to find regulations of candidate gene sets involved in the canonical cold-acclimation mechanisms, such as membrane remodeling, cryoprotectant (sugar) metabolism, ionic/ water balance or stress proteins.

\section{Results \\ Cold tolerance increased with acclimation duration}

Five-day old flies were either cold-acclimated at $10^{\circ} \mathrm{C}$ for various durations $(2 \mathrm{~h}, 6 \mathrm{~h}, 12 \mathrm{~h}, 24 \mathrm{~h}, 48 \mathrm{~h}, 72 \mathrm{~h}$, 6 days, i.e. $144 \mathrm{~h}$ or 9 days, i.e. $216 \mathrm{~h}$ ) or non-acclimated $(0 \mathrm{~h})$; this generated nine treatments of acclimation. Survival to acute $\left(-5^{\circ} \mathrm{C}\right.$ for $\left.1 \mathrm{~h}\right)$ and to chronic cold stress $\left(0^{\circ} \mathrm{C}\right.$ for $\left.24 \mathrm{~h}\right)$ as a function of acclimation is displayed in Fig. 1a and b, respectively. Regardless of sex, cold survival reached a maximum after $144 \mathrm{~h}$ (6 days) of acclimation (Fig. 1a and b). Globally, both acute or chronic cold stress survival increased with acclimation duration, reaching 98\% for males and $96 \%$ for females after $216 \mathrm{~h}$ (9 days) of acclimation (acute: $\chi^{2}=278.52$, p.value $<0.001$; chronic: $\chi^{2}=135.10$, p.value $<0.001$; Fig. 1a and b; Additional file 1: Figure S1). However, variations in survival rates were observed, for instance in males, survival was lower after $12 \mathrm{~h}$ of acclimation than after $6 \mathrm{~h}$ of acclimation (Fig. 1a and b). Overall, males showed a higher survival to acute and chronic cold stress than females (acute: $X^{2}=253.34$, p.value $<0.001$; chronic: $X^{2}$ $=91.509$, p.value $<0.001$; Fig. $1 \mathrm{a}$ and $\mathrm{b}$; Additional file 1: Figure S1). Females clearly showed improved cold survival with acclimation duration, whereas benefits in males were much less manifested due to their already-high basal tolerance (Additional file 1: Figure S1). These distinct patterns resulted in significant acclimation duration $\mathrm{x}$ sex interaction (acute: $\chi^{2}=10.75$, p.value $<0.01$; chronic: $\chi^{2}=48.70$, p.value $<0.001$; Fig. $1 \mathrm{a}$ and $\mathrm{b})$.

Mean critical thermal minimum $\left(\mathrm{Ct}_{\mathrm{min}}\right)$ of males and females are displayed in Fig. 1c. With no acclimation treatment (i.e. $0 \mathrm{~h}$ of acclimation), mean $\mathrm{Ct}_{\mathrm{min}}$ values were $5.4 \pm 0.15$ and $5.2 \pm 0.11{ }^{\circ} \mathrm{C}$ for males and females, respectively. Values gradually decreased with acclimation duration to reach $3.2 \pm 0.18$ and $2.7 \pm 0.12^{\circ} \mathrm{C}$ after $216 \mathrm{~h}$ acclimation, in males and females respectively $\left(\chi^{2}=\right.$ 220.95 , p.value $<0.001)$. $\mathrm{Ct}_{\min }$ values decreased similarly with acclimation in males and females (acclimation duration $x$ sex interaction: $\chi^{2}=2.09$, p.value $=0.14$ ).

Chill coma recovery time (CCRT) curves are shown in Fig. 1d and e, for males and females respectively. All statistics comparing the CCRT curves of the different treatments (Gehan-Breslow-Wilcoxon tests) are available 


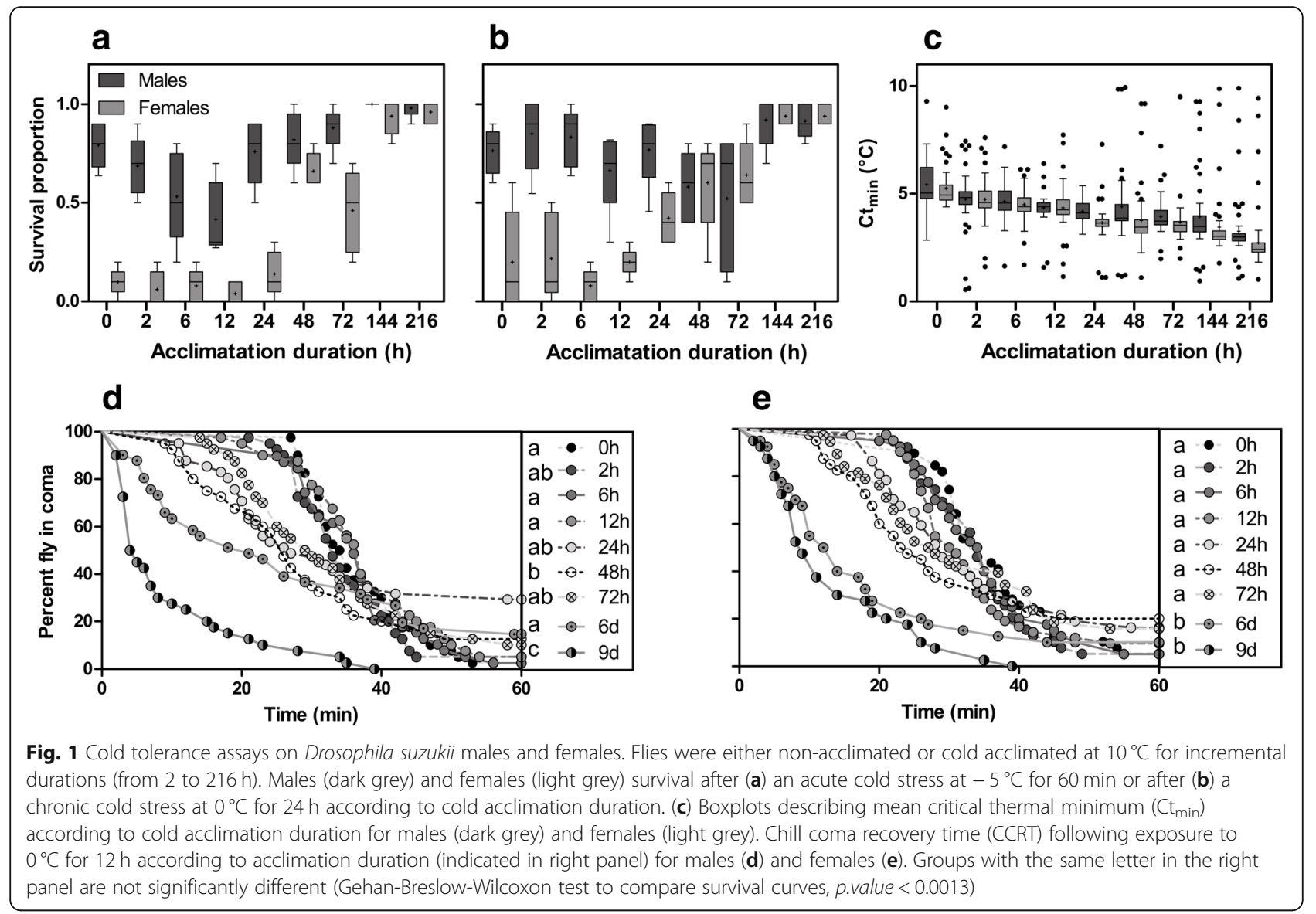

in Table 1. All flies from all treatments were in chill coma after $12 \mathrm{~h}$ at $0{ }^{\circ} \mathrm{C}$, but the recovery dynamics varied greatly with acclimation treatments. Globally, recovery time decreased with acclimation duration for both males and females, with non-acclimated flies showing the slowest recovery dynamics, and $216 \mathrm{~h}$ (9 days) acclimated flies the fastest.

Additional cold tolerance assays were performed to account for any physiological age distortion between control and acclimated flies. Indeed, the transcriptomic analysis were based on a comparison between control flies versus flies acclimated for 9 days at $10^{\circ} \mathrm{C}$. Even though aging is likely very limited at $10^{\circ} \mathrm{C}$, we reasoned that physiological age of flies might be slightly different between control flies (5d-old mature flies) and acclimated flies $\left(5 \mathrm{~d}\right.$-old mature flies +9 days at $\left.10^{\circ} \mathrm{C}\right)$. Using the developmental zero at which metabolic activity is supposed to stop $\left(7.2^{\circ} \mathrm{C}\right.$ in D. suzukii, [40]), we estimated that degree days (DD) accumulated during the acclimation period (i.e., $25 \mathrm{DD}$ for 9 days at $10^{\circ} \mathrm{C}$ ) would be less than two days at $25^{\circ} \mathrm{C}$ (i.e., $35 \mathrm{DD}$ ). Therefore, we compared cold tolerance (CCRT) of two control fly sets, one of $5 \mathrm{~d}$-old and the other of $7 \mathrm{~d}$-old, with the cold tolerance of acclimated flies $\left(5 \mathrm{~d}\right.$-old +9 days at $\left.10^{\circ} \mathrm{C}\right)$.
We confirmed that acclimated flies were much more cold tolerant than controls regardless of age (Additional file 1: Figure S2).

\section{RNA sequencing results and qPCRs validation of gene expressions}

From six libraries, comprising three true replicates (i.e. independent pools of 10 flies) of control females (COF1-3) and three of cold acclimated females (CAF1-3), we obtained a total of approximatively 198 million paired end reads, with an average Q30 of 95.13\%. After trimming, we obtained approximatively 180 million paired end reads. The mapping resulted in a mean of $71.11 \%$ mapped reads (Table 2). A total of 13,486 genes were annotated and used for differential expression analysis. This analysis highlighted 1583 up- and 1325 downregulated genes in cold acclimated flies, among them 378 were expressed exclusively in cold acclimated flies, and 331 only in control flies (Fig. 2a, Additional file 2: Tables S1 and S2). Expression patterns were validated with qPCRs on a selection of nine up- and downregulated genes (Fig. 2b) and were highly similar to expression levels resulting from the differential expression analysis of RNAseq 
Table 1 Comparisons of CCRT (chill coma recovery time) curves between the different acclimation durations, for males and females

\begin{tabular}{|c|c|c|c|c|c|c|c|c|c|c|c|c|c|c|c|c|c|}
\hline \multirow{2}{*}{\multicolumn{2}{|c|}{$\begin{array}{l}\text { Sex / acc. } \\
\text { Duration }\end{array}$}} & \multicolumn{2}{|l|}{$2 \mathrm{~h}$} & \multicolumn{2}{|l|}{$6 \mathrm{~h}$} & \multicolumn{2}{|l|}{$12 \mathrm{~h}$} & \multicolumn{2}{|l|}{$24 \mathrm{~h}$} & \multicolumn{2}{|l|}{$48 \mathrm{~h}$} & \multicolumn{2}{|l|}{$72 \mathrm{~h}$} & \multicolumn{2}{|l|}{$144 \mathrm{~h}$} & \multicolumn{2}{|l|}{$216 \mathrm{~h}$} \\
\hline & & p.value & $x^{2}$ & p.value & $x^{2}$ & p.value & $x^{2}$ & p.value & $x^{2}$ & p.value & $x^{2}$ & p.value & $x^{2}$ & p.value & $x^{2}$ & p.value & $x^{2}$ \\
\hline \multirow[t]{8}{*}{ Males } & $\mathrm{Oh}$ & 0.27 & 1.20 & 0.88 & 0.02 & 0.37 & 0.77 & 0.11 & 2.48 & $0.0004^{*}$ & 12.4 & 0.03 & 4.33 & 0.0027 & 8.99 & $<2.7 \mathrm{E}-05^{* * *}$ & 60.78 \\
\hline & $2 \mathrm{~h}$ & / & / & 0.44 & 0.57 & 0.10 & 2.70 & 0.16 & 1.90 & 0.004 & 8.29 & 0.13 & 2.20 & 0.0076 & 7.12 & $<2.7 \mathrm{E}-05^{* * *}$ & 58.07 \\
\hline & $6 \mathrm{~h}$ & / & / & / & / & 0.55 & 0.34 & 0.13 & 2.19 & $0.0012^{*}$ & 10.5 & 0.05 & 3.82 & 0.0048 & 7.96 & $<2.7 \mathrm{E}-05^{* * *}$ & 59.91 \\
\hline & $12 \mathrm{~h}$ & / & / & / & / & / & / & 0.12 & 2.32 & $0.0005^{*}$ & 12.2 & 0.02 & 4.77 & 0.0022 & 9.39 & $<2.7 \mathrm{E}-05^{* * *}$ & 61.1 \\
\hline & $24 \mathrm{~h}$ & / & / & / & / & / & / & / & / & 0.27 & 1.17 & 0.85 & 0.034 & 0.020 & 5.37 & $<2.7 \mathrm{E}-05^{* * *}$ & 46.0 \\
\hline & $48 \mathrm{~h}$ & / & / & / & / & / & / & / & / & / & / & 0.15 & 1.98 & 0.15 & 2.01 & $<2.7 \mathrm{E}-05^{* * *}$ & 39.8 \\
\hline & $72 \mathrm{~h}$ & / & / & / & / & / & / & / & / & / & / & / & / & 0.03 & 4.62 & $<2.7 \mathrm{E}-05^{* * *}$ & 49.98 \\
\hline & $144 \mathrm{~h}$ & / & / & / & / & / & / & / & / & / & / & / & / & / & / & $<2.7 \mathrm{E}-05^{* * *}$ & 19.69 \\
\hline \multirow[t]{8}{*}{ Females } & $\mathrm{Oh}$ & 0.47 & 0.51 & 0.40 & 0.70 & 0.03 & 4.29 & 0.04 & 3.97 & 0.003 & 8.38 & 0.04 & 3.88 & $<2.7 \mathrm{E}-05^{* * *}$ & 33.49 & $<2.7 \mathrm{E}-05^{* * *}$ & 55.57 \\
\hline & $2 \mathrm{~h}$ & / & / & 0.95 & 0.003 & 0.20 & 1.59 & 0.14 & 2.08 & 0.01 & 5.85 & 0.18 & 1.73 & $<2.7 \mathrm{E}-05^{* * *}$ & 30.85 & $<2.7 \mathrm{E}-05^{* * *}$ & 51.3 \\
\hline & $6 \mathrm{~h}$ & / & / & / & / & 0.24 & 1.32 & 0.17 & 1.83 & 0.01 & 5.87 & 0.17 & 1.82 & $<2.7 \mathrm{E}-05^{* * *}$ & 31.58 & $<2.7 \mathrm{E}-05^{* * *}$ & 52.56 \\
\hline & $12 \mathrm{~h}$ & / & / & / & / & / & / & 0.43 & 0.60 & 0.02 & 4.90 & 0.28 & 1.14 & $<2.7 \mathrm{E}-05^{* * *}$ & 31.00 & $<2.7 \mathrm{E}-05^{* * *}$ & 50.1 \\
\hline & $24 \mathrm{~h}$ & / & / & / & / & / & / & / & / & 0.13 & 2.24 & 0.58 & 0.29 & $<2.7 \mathrm{E}-05^{* * *}$ & 24.63 & $<2.7 \mathrm{E}-05^{* * *}$ & 38.99 \\
\hline & $48 \mathrm{~h}$ & / & / & / & / & / & / & / & / & / & / & 0.13 & 0.82 & $<2.7 \mathrm{E}-05^{* * *}$ & 15.83 & $<2.7 \mathrm{E}-05^{* * *}$ & 29.02 \\
\hline & $72 \mathrm{~h}$ & / & / & / & / & / & / & / & / & / & / & / & / & $<2.7 \mathrm{E}-05^{* * *}$ & 19.78 & $<2.7 \mathrm{E}-05^{* * *}$ & 34.5 \\
\hline & $144 \mathrm{~h}$ & / & / & / & / & / & / & / & / & / & / & / & / & / & / & 0.18 & 1.75 \\
\hline
\end{tabular}

CCRT curves are available on Fig. 1d and e. p. values has been adjusted using Bonferroni correction: ${ }^{*}<0.0013 ;{ }^{* *}<0.0002 ;{ }^{* * *}<2.7 \mathrm{E}-05$ (Gehan-Breslow-Wilcoxon tests)

(Spearman correlation: p.value $<0.01$; linear regression: p.value $\left.<0.001 ; \mathrm{r}^{2}=0.96\right)$. The slope of this relation $(0.89 \pm 0.07)$ was not different from $1(F=2.37$; p.value $=0.14)$.

\section{Gene ontology (GO) terms enrichment on differentially expressed genes revealed implications of several physiological functions in cold acclimated flies}

Two strategies are often adopted for enrichment analysis of pathways: the analysis of all differentially expressed genes together or the analysis of up- and downregulated genes separately. The analysis through the separate strategy is supposed to be more reasonable and powerful than the strategy with all differential genes together [41]. Hence, in the present work, GO terms enrichment analyses were performed separately on up- and downregulated gene sets in acclimated flies using GO-TermFinder
[42]. For upregulated genes, enrichment analyses resulted in 20 significant GO-terms for cell component. These indicated that regulated genes were mainly located in 'plasma membrane' or 'synapse'. Analyses also detected 26 enriched GO-terms for molecular functions, many of which were redundant and designated enrichment of 'ion transport' and 'signaling across membranes'. Finally, for biological process 30 different, but sometime redundant, GO-terms were enriched. The most significant involved 'ion transmembrane transport,' 'response to stimulus', 'cell communication,' 'signal transduction' and various nervous system processes. 'Carbohydrate homeostasis' was also found to be enriched (Fig. 3, Additional file 2: Tables S3 to S5). For the set of downregulated genes, analyses resulted in three significant GO-terms for cell component (i.e., 'external encapsulating structure', 'chorion', and 'intracellular membrane-bounded organelle'),

Table 2 Summary of RNA sequencing metrics

\begin{tabular}{lllllll}
\hline Sample & Yield (Mbp) & N Reads & \%Q30 & Mean Q & N Reads after trimming & \% Mapping \\
\hline CAF1 & 8.297 & $33,187,088$ & 94.98 & 35.76 & $30,158,494$ & 71.4 \\
CAF2 & 7.166 & $28,665,463$ & 94.84 & 35.7 & $26,025,539$ & 70.9 \\
CAF3 & 6.782 & $27,126,385$ & 94.96 & 35.75 & $24,736,334$ & 71.5 \\
COF1 & 9.01 & $36,040,513$ & 95.38 & 35.8 & $32,867,578$ & 69.7 \\
COF2 & 11.272 & $45,089,307$ & 95.29 & 35.78 & $41,064,935$ & 70.2 \\
COF3 & 6.922 & $27,686,685$ & 95.38 & 35.81 & $25,285,497$ & 73 \\
\hline
\end{tabular}

Yield $(\mathrm{Mbp})$ number of bases in mega bases, Q quality score, \%Q30 percentage of bases with a quality score of at least 30 . CAF cold acclimated females, COF Control Females 


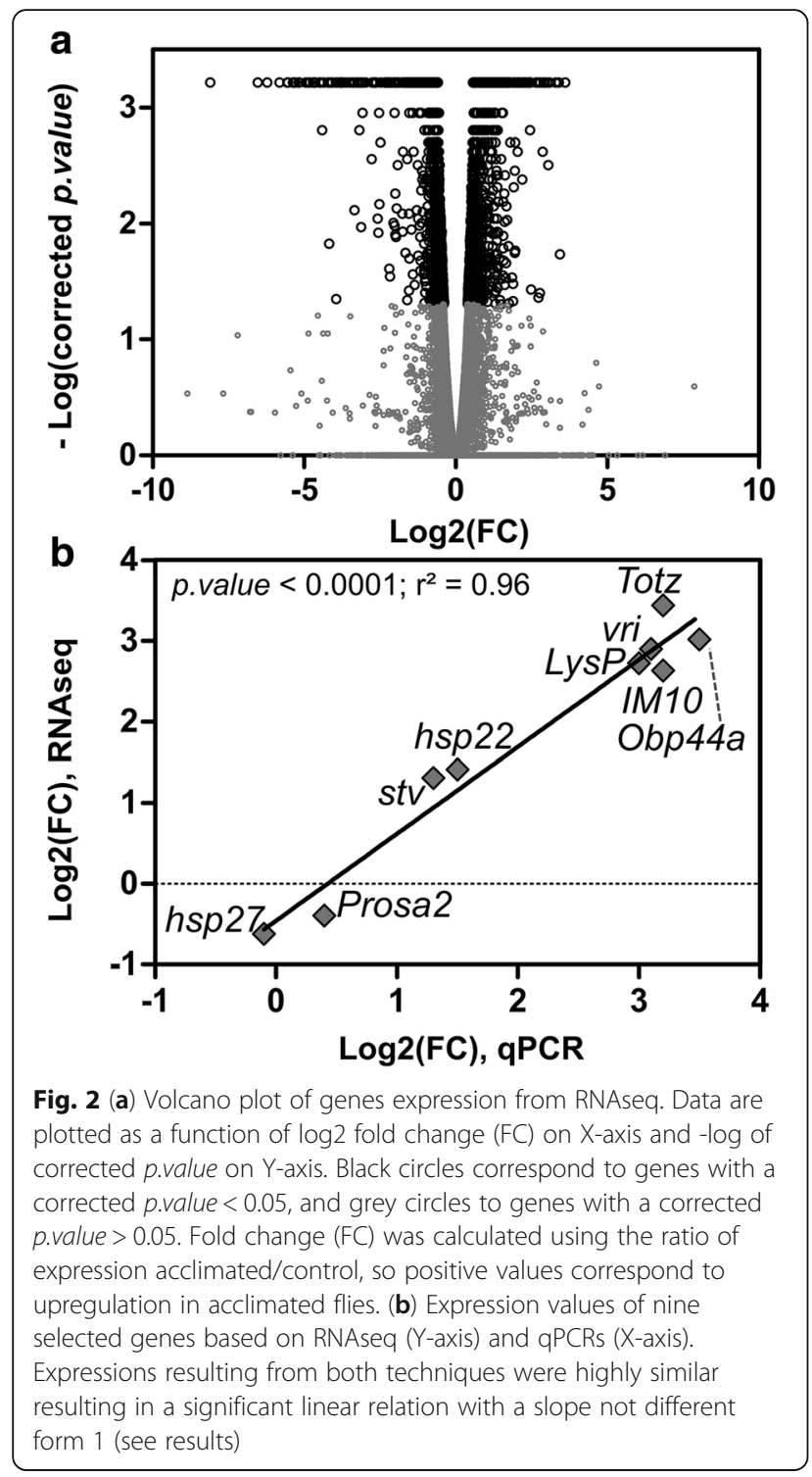

no GO-term was enriched for molecular function, and 11 GO-terms were enriched for biological process, including 'eggshell formation,' vitelline membrane formation,' 'carboxylic acid catabolic process' or 'protein folding' (Fig. 4, Additional file 2: Tables S6 to S8). Results of these analyses were very similar to outputs obtained with STRING annotation tool [43], which detected similar enriched GO-terms. This latter analysis also found a single enriched KEGG pathway: 'starch and sucrose metabolism' (Additional file 2:Tables S9 and S10).

To facilitate interpretations, functional redundancy among GO-terms was reduced, and the presence of superclusters of overrepresented GO-terms was visualized in treemaps using REVIGO program [44]. In the treemaps, representative GO clusters are shown as rectangles whose size reflects the $p$-values. Related GO-terms are then joined into superclusters that present a particular relevance. For cellular component, REVIGO found the following superclusters: 'integral component of plasma membrane' and 'chorion', for up- and downregulated genes respectively (Figs. $3 \mathrm{a}$ and $4 \mathrm{a}$ ). For molecular functions, one main GO supercluster was found for upregulated genes: 'ion transmembrane transporter activity' (Fig. 3b). For biological processes, three superclusters were found from upregulated genes: 'G-protein coupled receptor (GPCR) signaling pathway', 'cation transport' and 'system process' (Fig. 3c). GO-terms related to downregulated genes formed a single supercluster: 'chorion-containing eggshell formation' (Fig. 4b).

Gene Ontology (GO) enrichment analyses were also performed in STRING (considering false discovery rate, i.e. FDR, <0.05) and provided exactly same output as GO:term finder analyses (these results are available in Additional file 2: Tables S9 and S10). As shown in Figs. 5 and 6 , the up and down regulated genes had significant associations and intricate interactions (protein-protein interactions enrichment $p$-value $=1.0 \mathrm{e}-16$ for both up and down regulated genes). This indicates that, in response to acclimation, many functionally related genes were concurrently regulated. Genes involved in the major GO-terms superclusters detected in REVIGO (see Figs. 3 and 4) are highlighted within the networks with different colors (see Figs. 5 and 6 captions) and this revealed that these GO superclusters involved many highly connected genes.

In the present work, we considered genes as differentially expressed when q.values (FDR-adjusted p.value) were $<0.05$. However, classically, differentially expressed genes can be also defined using a fold change $(\mathrm{FC})$ cutoff as a supplementary parameter [45]; however the functional/biological meaning of cutoffs are questionable. To confirm our functional analysis, we performed another GO-terms enrichment analysis on differentially expressed gene sets with a FC cutoff $>1.5$. Globally, similar outputs were found, with the same main GO-terms being enriched with or without FC cutoff. These results are available in Additional file 2: Table S12.

\section{Discussion}

Acclimation increases cold tolerance of Drosophila suzukii We subjected $D$. suzukii adults to incremental acclimation durations to determine cold pre-exposure duration needed to acquire high cold tolerance. Very short acclimation durations ( 2 or $6 \mathrm{~h}$ ) at mildly low temperature did not markedly improved cold tolerance (Fig. 1). In previous studies, rapid cold hardening had either no impact [35], or a positive impact [33, 34] on D. suzukii cold tolerance. To observe rapid cold hardening response, protocols typically involve pre-exposures to stressful temperatures (around $0^{\circ} \mathrm{C}$ ) [46]. The temperature used in the present study to acclimate insects $\left(10^{\circ} \mathrm{C}\right)$ was probably not low/stressful enough to trigger a rapid 


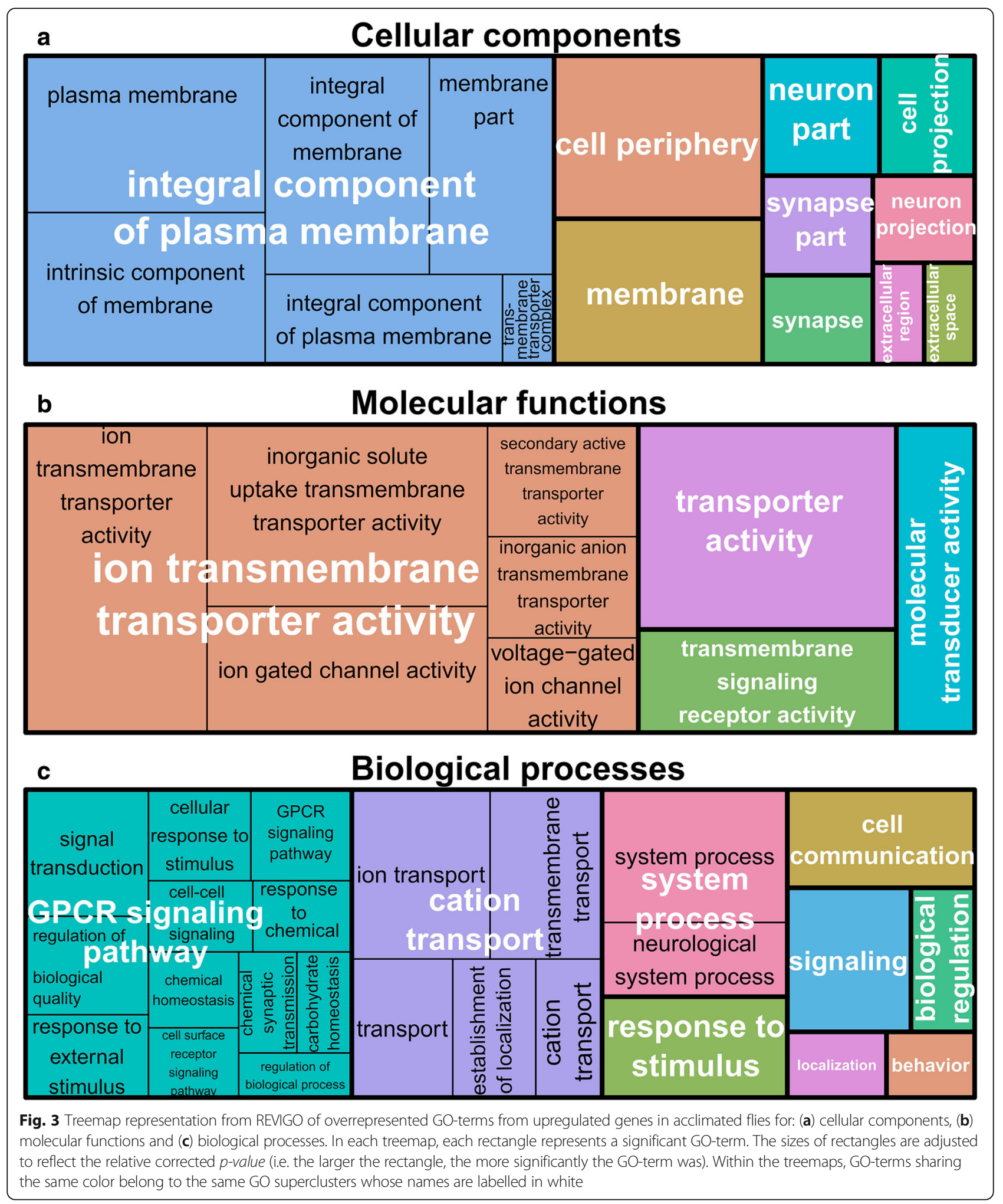

acquisition of cold tolerance. On the other hand, as reported in other insects $[47,48]$, cold tolerance increased when acclimation duration increased. We found that survival was high and maximum after six days of acclimation and then remained high with longer acclimation durations. Despite acute and chronic survival reached a plateau after six days of acclimation, CCRT and $\mathrm{Ct}_{\mathrm{min}}$ decreased further after nine days of 


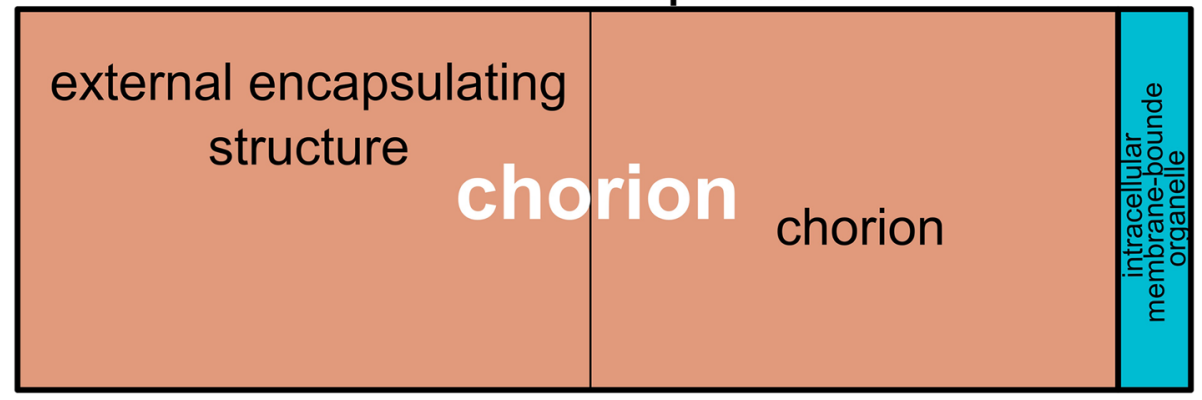

b

Biological processes

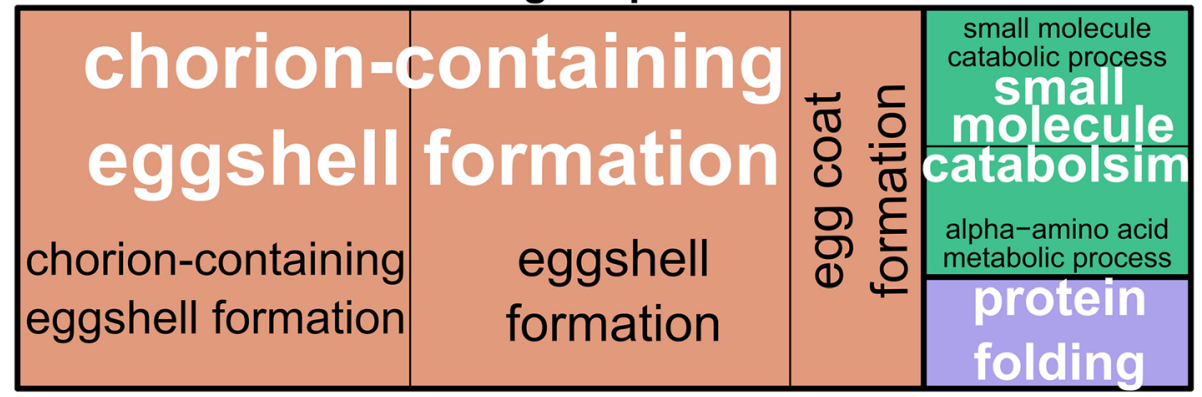

Fig. 4 Treemap representation from REVIGO of overrepresented GO-terms from downregulated genes in acclimated flies for (a) cellular components and (b) biological processes. In each treemap, each rectangle represents a significant GO-term. The sizes of rectangles are adjusted to reflect the relative corrected $p$-value (i.e. the larger the rectangle, the more significantly the GO-term was). Within the treemaps, GO-terms sharing the same color belong to the same GO superclusters whose names are labelled in white

acclimation. Our results are in accordance with previous findings showing that in D. suzukii acclimation at mildly low temperature for several consecutive days deeply promotes adult cold tolerance $[25,35,38]$. We therefore confirm that D. suzukii displays high and efficient cold tolerance plasticity; this capability likely contributes to its invasive success in temperate cold regions.

\section{Activity of ion transmembrane transporters seems important for acclimation}

GO-terms enrichment analysis revealed that the major part of upregulated genes were located in cell membranes, neurons and synapses. Molecular functions mainly involved 'ion transmembrane transporter activity' and many biological processes involved 'ionic transporter activity' (Figs. 3 and 5). Involvement of similar GO-terms has previously been reported in $D$. melanogaster flies that developed at low temperature $\left(13^{\circ} \mathrm{C}\right)$ [49-51]. Multiple genes linked to 'ion transmembrane transport activities' were upregulated in cold acclimated flies $\left(\mathrm{Ca}^{2+}, \mathrm{Na}^{+}\right.$or $\mathrm{K}^{+}$ channels; $\mathrm{K}^{+}$transporters; $\mathrm{Na}^{+}$transporters; ATPase ion transporters; $\mathrm{Na}^{+} / \mathrm{H}^{+}$transporters; transmembrane organic anion transporters; see Table 3). Genes linked to ion channels are intimately correlated to cold tolerance acquisition in Gryllus pennsylvanicus [29]. Under permissive thermal conditions, insects maintain ion homeostasis by compensating the natural leakage of ions across membranes through active transports [13, 19]. Cell membranes are highly thermosensitive macromolecules and temperature decrease induces changes of membrane fluidity, and in extreme cases, transition of membrane phospholipidic bilayer from a liquid crystalline phase to a more rigid lamellar gel phase $[20,52]$. These conformation changes can in turn alter ion permeability of membranes [52], provoking loss of ions homeostasis [20, 53]. Functions of membrane-embedded enzymes, proteins and transporters could be altered by these changes in membrane fluidity $[52,54,55]$, but also by direct kinetic effects of cold temperatures $[19,31,56]$, participating in the deregulation of ion balance $[13,31,32,57,58]$. Alteration of ion equilibrium can directly damage cells and tissues [31, 57 , $59,60]$ and provoke depolarization of membranes, altering action potentials of muscles and neuron cells, conducting to loss of neuromuscular functions and coma [13, 60-67]. In insects, cold tolerance acquisition is correlated with preservation of transmembrane ion balance [31, 57, 64, 68]. This has been reported in Drosophila flies [32, 64, 69], including $D$. suzukii [70]. One of the underlying mechanisms of ion balance preservation is likely the plasticity of ion channel thermal sensitivity and the recruitment of ion transporters [13, 19, 64, 69, 71, 72]. The maintenance of ion homeostasis allows electrochemical properties of membranes to be persevered, guaranteeing neuromuscular functions $[13,19,64]$. Our data strongly suggest that cold 


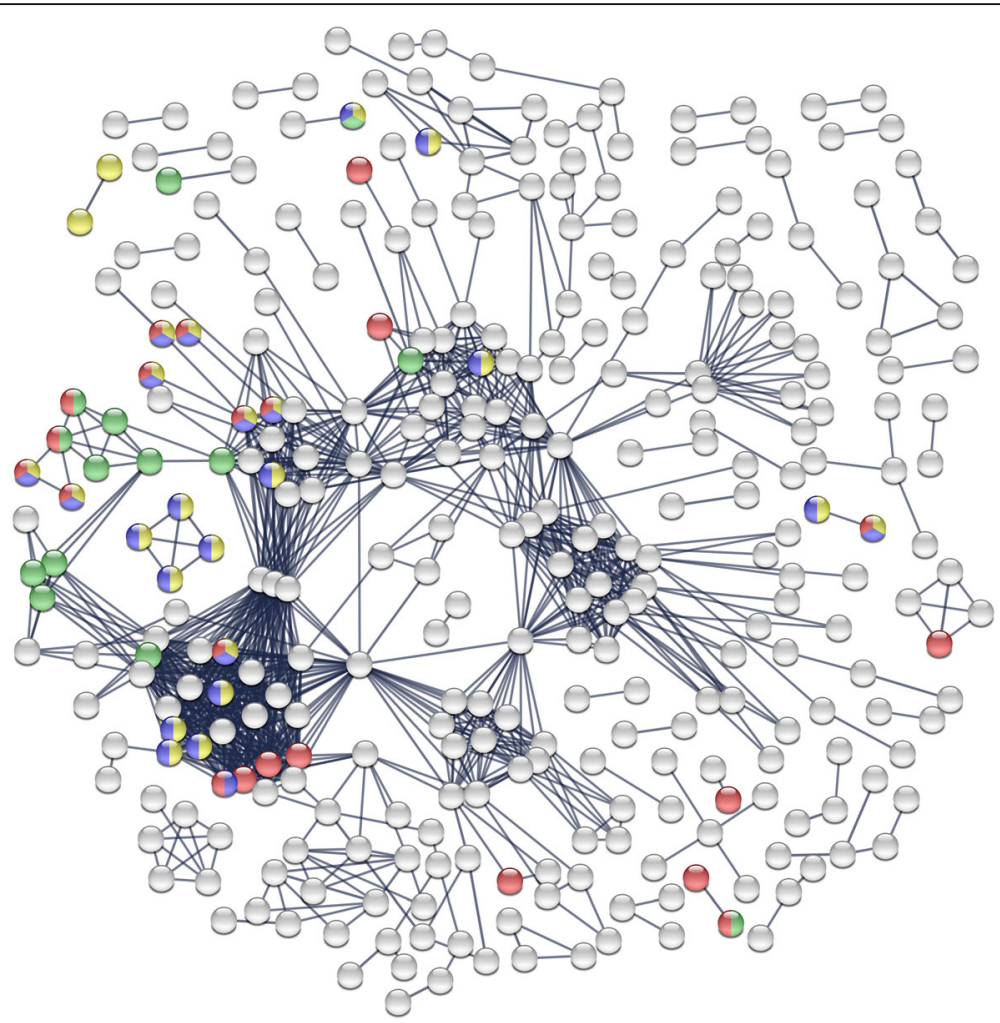

Fig. 5 Interaction network resulting from the set of upregulated genes in acclimated flies. Each node represents a protein, and each line represents an interaction between two proteins. The gene sets were analyzed for putative protein-protein interactions using STRING program with default settings, with exception of the confidence interactions value that was set to high confidence (score $>0.9)$. Disconnected nodes are not represented. Genes involved in the major GO superclusters detected in REVIGO (see Fig. 3) are highlighted with different colors: Cellular component: red: 'integral component of plasma membrane'; Molecular functions: blue: 'ion transmembrane transporter activity'; Biological processes: yellow: 'cation transport'; green: 'GPCR signaling pathway'

acclimation in D. suzukii induces plastic expression of genes that play essential roles in transport activity of ions across membranes, most likely to prevent disruption of ion homeostasis that may occur at low temperature [70].

\section{Genes related to neuronal activity are positively correlated with cold acclimation}

Loss of neuromuscular function at low temperature may be linked to impairment of synaptic actions [19]. Indeed neurotransmitter release depends on the activity of $\mathrm{Ca}^{2+}$ channels, which may be impaired by depolarization [72] and altered fluidity [73] of membranes at low temperature [52]. Here we observed regulation of genes located in neurons and synapses (Fig. 3a). In addition, several genes coding for neurotransmitter receptors were regulated after cold acclimation (GABA; acetylcholine; dopamine; serotonin; glutamate; Table 3). In cold acclimated G. pennsylvanicus several genes linked to neurotransmitters were also upregulated [29], and in diapausing females of Drosophila montana maintained for several months at $4{ }^{\circ} \mathrm{C}$, microarrays revealed up regulation of genes involved in dopamine and serotonin synthesis [74]. Furthermore, a previous study that explored transcriptional adjustments in D. suzukii showed that the GO-term 'Neurotransmitter transporter activity' was also associated with the winter-phenotype [37]. These altered gene expressions are likely related to adjustments of neurotransmitter activities at the synaptic level in order to compensate cold deleterious effects.

\section{Cold acclimation alters expression of genes involved in cellular signaling}

One of the main GO-term superclusters from upregulated genes was 'G-protein coupled receptor (GPCR) pathway' that comprised many GO-terms related to signal transduction or signaling (Figs. $3 \mathrm{c}$ and 5). 'Response to stimulus' and 'cell communication' were also highlighted among the most enriched GO-terms. This suggests a major role of genes related to cellular signaling pathways for cold tolerance acquisition. In $D$. ananassae, populations selected for cold tolerance showed upregulation of GO-terms implied in 'cell communication' and 'signaling' [75]. Interestingly, cold acclimated G. pennsylvanicus also showed upregulation of genes 


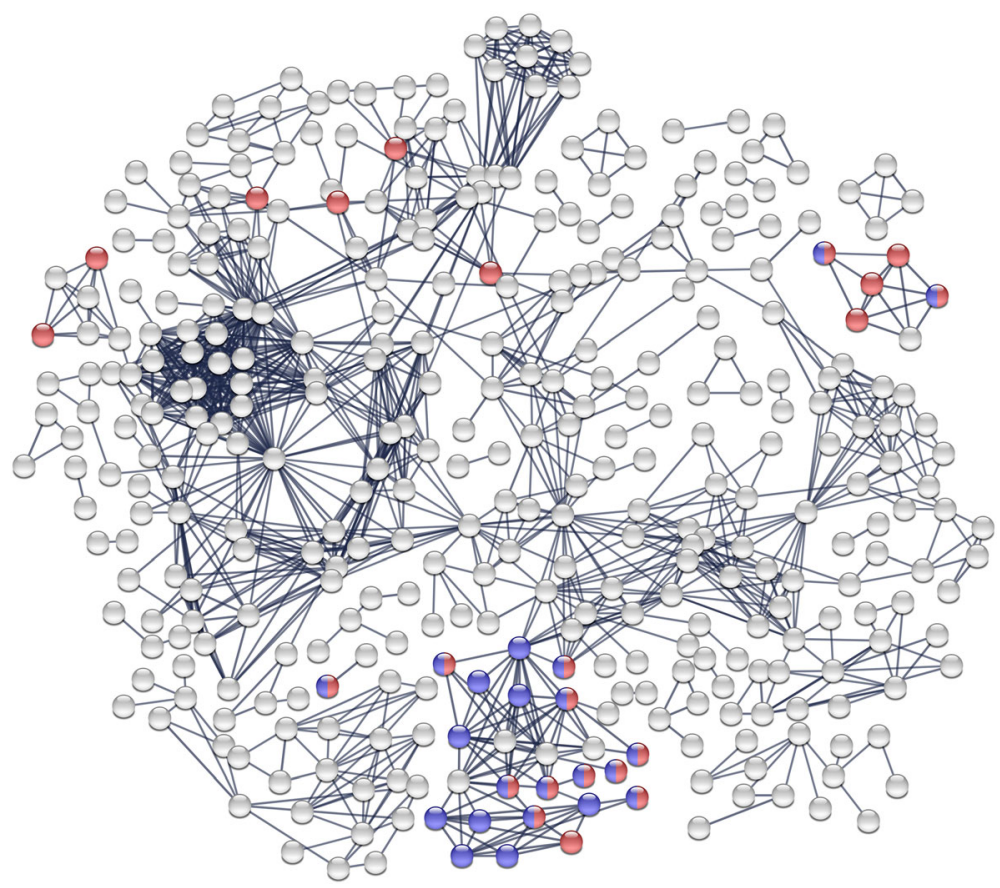

Fig. 6 Interaction network resulting from the set of down regulated genes in acclimated flies. Each node represents a protein, and each line represents an interaction between two proteins. The gene sets were analyzed for putative protein-protein interactions using STRING program with default settings, but with high confidence interactions value (score $>0.9$ ). Disconnected nodes are not represented here. The thickness of the edges are related to confidence in data (thicker lines indicate stronger evidence for interaction). Genes involved in the major GO superclusters detected in REVIGO (see Fig. 4) are highlighted in color: Cellular component: blue: 'chorion'; Biological processes: red: 'chorion-containing eggshell formation'

linked to 'GPCR activity' [29]. Among genes involved in the enriched GO-term 'GPCR signaling pathway', we observed several founding members the methuselah family (mth, mthl12, mthl14, mthl15, mthl9) that were all upregulated in acclimated insects. These genes are Drosophila GPCRs involved in the modulation of life span and stress response including heat, starvation, and oxidative damage [76]. GPCRs are transmembrane receptors, initiators of signal transduction and cellular responses, and are involved in a large panel of physiological functions [77]. Stress signaling and thermal plasticity in insects is regulated by protein kinases [78-80], and protein kinase signaling cascades can be activated by GPCRs [81]. Upregulated GO-terms linked to GPCR activity could therefore be linked to a global response or sensing of low temperatures, initiating transduction signal cascades triggering cold acclimation.

We identified two genes coding for $\mathrm{G}$ protein-coupled inwardly-rectifying potassium channels (Irk2 and Irk3) that were regulated in cold acclimated flies (see Table 3). These ion channels are primary effectors of GPCR, and participate in hyperpolarization of cell membranes [82]. As previously discussed, ion channel activities are of major importance to counterbalance disturbance of ionic homeostasis due to cold temperatures. Regulation of transcripts linked to GPCR activity could therefore also be linked to ion homeostasis maintenance, through adjustment of ion channels.

\section{Possible role of carbohydrate metabolism in response to cold acclimation}

We expected to observe regulation of candidate genes involved in some of the canonical cold-acclimation mechanisms, such as membrane modifications or cryoprotectant (sugar) metabolism. The GO-term 'carbohydrate homeostasis' was indeed enriched in acclimated flies as well as the KEGG pathway 'starch and sucrose metabolism'. Genes upregulated in acclimated flies included several enzymes (Hex-t1, Hex-C, Pepck1) playing key roles in carbohydrate metabolism and sugars interconversions. We also noted the upregulation of an adipokinetic hormone receptor $(A k h R)$, a GPCR neuropeptide/hormone receptor involved in carbohydrate and lipid homeostasis [83]. We also found upregulation of desaturase (Desat1), a gene well known to be involved in the synthesis of unsaturated fatty acids [84]. Desaturases play roles in cold-induced phospholipid restructuring [54] and upregulation of Desat genes has been correlated with enhancement of cold hardiness [85, 86]. Desat1 and Desat2 were also reported to be upregulated in 
Table 3 List of genes discussed in the text

\begin{tabular}{|c|c|c|c|}
\hline Gene & Gene ID ${ }^{a}$ & $F C^{b}$ & Function or process \\
\hline NaCP60E & DS10_00003598 & 1.77 & Transporters: ion channels \\
\hline Ca-alpha1D & DS10_00000955 & 1.54 & \\
\hline$K C N Q$ & DS10_00002789 & 1.68 & \\
\hline$H k$ & DS10_00004874 & 1.51 & \\
\hline Irk2 & DS10_00011692 & 2.01 & \\
\hline Irk3 & DS10_00006400 & 2.44 & \\
\hline Vha14-2 & DS10_00012657 & Only in CAF & ATPase ion transporters \\
\hline Vha68-1 & DS10_00007687 & 1.44 & \\
\hline VhaAC39-2 & DS10_00009944 & Only in CAF & \\
\hline VhaPPA1-2 & DS10_00011222 & Only in CAF & \\
\hline ppk15 & DS10_00012645 & Only in CAF & Sodium transporters \\
\hline ppk17 & DS10_00000507 & 2.49 & \\
\hline ppk5 & DS10_00010923 & Only in CAF & \\
\hline ppk9 & DS10_00003499 & Only in CAF & \\
\hline Oatp30B & DS10_00001585 & 1.49 & Organic anion transporters \\
\hline Oatp33Ea & DS10_00008440 & 2.64 & \\
\hline Oatp33Eb & DS10_00008442 & 1.50 & \\
\hline Oatp58Dc & DS10_00002075 & 2.44 & \\
\hline Nhal & DS10_00001446 & 1.38 & Sodium:proton transporters \\
\hline Nha2 & DS10_00010553 & 2.23 & \\
\hline Nhe2 & DS10_00001057 & 1.90 & \\
\hline$G A B A-B-R 2$ & DS10_00012213 & 2.08 & Neurotransmitter receptors \\
\hline nAChRbeta2 & DS10_00012765 & 2.56 & \\
\hline nAChRalpha7 & DS10_00004780 & 1.57 & \\
\hline DopEcR & DS10_00010177 & 2.58 & \\
\hline $5-H T 1 B$ & DS10_00005814 & 2.44 & \\
\hline Grip & DS10_00008207 & 1.59 & \\
\hline GluRIIE & DS10_00012665 & 2.45 & \\
\hline mth & DS10_00007901 & Only in CAF & GPCR involved in life span and stress response \\
\hline$m t h / 12$ & DS10_00003566 & 2.63 & \\
\hline$m t h / 14$ & DS10_00004634 & 1.71 & \\
\hline$m t h / 15$ & DS10_00000453 & 2.07 & \\
\hline mth/9 & DS10_00004608 & 1.77 & \\
\hline Hex- $t 1$ & DS10_00012733 & Only in CAF & Carbohydrate metabolism \\
\hline Hex-C & DS10_00005493 & 1.46 & \\
\hline Pepck1 & DS10_00005716 & 1.58 & \\
\hline$A k h R$ & DS10_00001466 & 2.56 & Carbohydrate and lipid homeostasis \\
\hline Desat1 & DS10_00012265 & 2.07 & Synthesis of unsaturated fatty acids \\
\hline $\mathrm{Hsc} 70-2$ & DS10_00009454 & 0.27 & Molecular chaperones or co-chaperones \\
\hline Hsp60C & DS10_00006901 & 0.68 & \\
\hline Hsp27 & DS10_00003843 & 0.65 & \\
\hline$H I P-R$ & DS10_00006110 & 0.76 & \\
\hline Totz & DS10_00013345 & 10.86 & \\
\hline Hsp22 & DS10_00003839 & 2.66 & \\
\hline
\end{tabular}


Table 3 List of genes discussed in the text (Continued)

\begin{tabular}{llll}
\hline Gene & Gene ID & $F C^{\mathrm{b}}$ & Function or process \\
\hline Cp7Fb & DS10_00006848 & 0.02 & Structural gene for eggshell formation (chorion) \\
Cp7FC & DS10_00006849 & 0.04 & \\
Cp15 & DS10_00003769 & 0.04 & \\
Cp16 & DS10_00003771 & 0.01 & \\
Cp18 & DS10_00003768 & 0.00 & \\
Cp19 & DS10_00003770 & 0.03 & \\
Cp36 & DS10_00006850 & 0.09 & \\
Cp38 & DS10_00006851 & 0.09 & \\
Yp1 & DS10_00004890 & 0.13 & \\
Yp2 & DS10_00004891 & 0.11 & Oogenesis; vitelline membrane formation gene for the yolk (Vitellogenin) \\
Yp3 & DS10_00008400 & 0.16 & \\
Vm26Aa & DS10_00007679 & 0.11 & \\
Vm26Ab & DS10_00008464 & 0.20 & \\
Vm32E & DS10_00001909 & 0.11 & \\
Vm34Ca & DS10_00001679 & 0.10 & \\
\hline
\end{tabular}

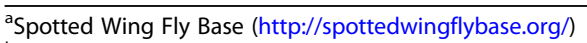

${ }^{b}$ Positive and negative values of fold change (FC) for upregulated and downregulated in acclimated flies respectively. CAF cold acclimated females, COF Control Females

diapausing D. montana females [87], but downregulation of Desat genes was reported in cold-acclimated Drosophila virilis group species [88]. Profiling with various 'Omics' techniques has provided supporting evidence for changes in carbohydrate metabolism and accumulation of sugars (particularly glucose, sucrose, fructose and trehalose) after both rapid and gradual cold acclimation in Drosophila [22, 27, 51, 89-91]. Our observation supports the general view that regulation of carbohydrate and lipid metabolism is an element of cold tolerance acquisition in D. suzukii [25, 37].

\section{Minor changes in stress genes expression in response to cold acclimation}

We expected to find regulation of genes involved in stress response. Functional annotation revealed 'protein folding' as enriched GO-term associated to downregulated genes in acclimated flies. Heat shock chaperones, such as Hsc70-2, Hsp60C, Hsp 27 or HIP-R (a co-chaperone), were downregulated in acclimated flies. $\mathrm{Hsc70-2}$ and $\mathrm{Hsp} 60 \mathrm{C}$ are constitutively expressed and not known to be cold-responsive [92]. There is a constant need for chaperone assistance during de novo protein folding and refolding of polypeptide chains [93], and hence, the reduced expression of heat shock chaperones in cold acclimated flies may be linked to reduced de novo protein folding at mild low temperature. We found no clear indication of stress genes being upregulated in acclimated flies, except Hsp22 (FC=2.6) or Totz $(\mathrm{FC}=$ 10); the latter was among the most upregulated genes in cold acclimated flies (Fig. 2b, Table 3). Totz belongs to
Turandot family; these genes are part of a humoral stress reaction unlike the heat shock response which mainly deals with the intracellular accumulation of denatured proteins [94]. Turandot genes also respond to other types of stress such as heat, UV or oxidative agents like paraquat [94, 95]. Turandot genes have also been shown to respond to low temperature likely because cold activates immune pathways $[95,96]$.

\section{Apparent decrease in oogenic activity with cold acclimation}

Many genes, relatively less expressed in cold acclimated flies, were involved in 'chorion and eggshell formation' (forming a main GO supercluster) (Figs. 4 and 6). Genes coding for chorion proteins, yolk proteins or vitelline membrane proteins were among the most downregulated genes in acclimated flies (see Table 3). In D. melanogaster, egg production is highest between 18 and $23^{\circ} \mathrm{C}$ and is strongly reduced at temperatures below or above this range [97, 98]. Expression of chorion-related genes follows this pattern as highest expression has been reported at intermediate temperatures [49]. The lowest developmental thermal threshold for ovarian maturation is generally around $10-12{ }^{\circ} \mathrm{C}$ in temperate drosophilids [99]. In D. suzukii, studies reported a reproductive dormancy mainly due to development at low temperature $[33,34,37]$. This reproductive arrest has also been associated with reduced expression of yolk protein gene (Yp1) [34]. Following the release of cold-induced dormancy, all yolk proteins transcripts have been found to be upregulated in D. melanogaster [100]. Reduced 
expression of genes related to oogenesis in acclimated D. suzukii females suggests a dormancy syndrome. In our experimental design, all flies developed and remained 5 days at $25^{\circ} \mathrm{C}$ after eclosion for maturation before treatment; therefore, all females contained mature eggs before they were cold acclimated. The gene patterns we observe here could translate a reduced oogenic activity at low temperature. Interestingly, Lirakis et al., [101] provided a very detailed study of oogenesis in a range of dormancy-inducing conditions in D. melanogaster. They reported that one-week old mature flies (maintained at $25^{\circ} \mathrm{C}$ ) had active oogenesis and mature eggs. When these one-week old mature flies were transferred to dormancy-inducing conditions $\left(10^{\circ} \mathrm{C}, 10 \mathrm{~L}: 14 \mathrm{D}\right)$, mature eggs were still present but oogenesis was stopped. Hence, they demonstrated that a dormancy-like phenotype (i.e. block of oogenesis) can be observed in mature flies when exposed to low temperature. In our setting, mature D. suzukii flies were acclimated by transferring them from 25 to $10{ }^{\circ} \mathrm{C}$ for 9 days. Just as in D. melanogaster, this situation could have stopped oogenic activity, explaining the relatively lower expression of genes involved in chorion and eggshell formation. It is not clear whether arrest of oogenesis is a passive consequence of low temperature with no adaptive value for cold tolerance or whether this mechanism is an active protective strategy. Data from drosophila species support that cold-induced oogenesis arrest (via quiescence or diapause) is actually part of an integrated mechanism of cold adaptation and cold stress tolerance mechanism $[99,101]$.

\section{Conclusions}

This work provides a characterization of transcriptomic changes in response to cold acclimation in D. suzukii. Cold tolerance of $D$. suzukii gradually increased with acclimation duration leading to highly cold-hardy phenotype, adding to the body of evidence that this fly possesses high thermal plasticity. We observed major transcriptional remodeling after cold acclimation, primarily involving ion transport and various signaling pathways across membranes and within neuronal parts, and a decrease of the reproductive (oogenesis) function. We suggest these mechanisms represent the core part of the physiological strategy of cold tolerance acquisition in D. suzukii. This study provides a list of new candidate genes related to cold tolerance in this fly. In particular, we have highlighted regulation of many genes of interest playing putative roles in ion transport and homeostasis. These processes determine neuromuscular functions, which are highly affected by low temperature, and therefore, constitute the fundamentals of insect cold tolerance [13]. Despite that acclimation treatments used in laboratory settings are not fully ecologically relevant, it is probable that molecular mechanisms similar to those described in the present study may occur in fields during seasonal acclimatization when temperatures progressively drop in the fall. From an applied point of view, cold acclimation may be useful for ongoing sterile/incompatible insect technique programs against $D$. suzukii [9]. After industrial production of males, insects need to be stored at low temperature [102] and cold acclimation could be used to prime insects and extend their shelf life. Insects may also be thermally conditioned before inundative to mitigate thermal stress in fields.

\section{Methods}

Flies' rearing conditions and acclimation procedure

The D. suzukii line used in this work is a population collected from infested fruits originated from different locations in Trentino (Italia), and brought to the Vigalzano station of the Edmund Mach foundation $(46.042574 \mathrm{~N}$, $11.135245 \mathrm{E})$ in 2011. This line was sent to our laboratory (Rennes, France) in early 2016, and has been reared under lab conditions ever since. Flies were reared in glass bottles $(100 \mathrm{~mL})$ and supplied ad libitum with a carrot-based diet (for $1 \mathrm{l}$ : agar: $15 \mathrm{~g}$, sucrose: $50 \mathrm{~g}$, carrot powder: $50 \mathrm{~g}$, brewer yeast: $30 \mathrm{~g}$, cornmeal: $20 \mathrm{~g}$, kalmus: $8 \mathrm{~g}$, Nipagin: $8 \mathrm{~mL}$ ). Flies were kept in incubators (Model MIR-154-PE; PANASONIC, Healthcare Co., Ltd. Gunma, Japan) at $25^{\circ} \mathrm{C}, 12 \mathrm{~L}: 12 \mathrm{D}$. Males were identified visually and were manually separated from females with an aspirator without $\mathrm{CO}_{2}$ to avoid stress due to anesthesia [103]. Acclimation was induced as follows: 5-day old flies were held either in the rearing conditions (i.e. non-acclimated treatment) or they were cold-exposed at $10^{\circ} \mathrm{C}$ in incubators (Model MIR-154-PE; PANASONIC, Healthcare Co., Ltd. Gunma, Japan) for $0 \mathrm{~h}, 2 \mathrm{~h}, 6 \mathrm{~h}, 12 \mathrm{~h}, 24 \mathrm{~h}, 48 \mathrm{~h}, 72 \mathrm{~h}$, 6 days $(144 \mathrm{~h})$ or 9 days $(216 \mathrm{~h})$, in order to generate nine treatments of incremental acclimation durations. The acclimation temperature of $10^{\circ} \mathrm{C}$ was chosen because this temperature is cold enough to induce an acclimation response in D. suzukii without causing mortality in adults [25]. Photoperiod during thermal treatments was standardized at $12 \mathrm{~L}: 12 \mathrm{D}$.

\section{Cold tolerance assays \\ Acute cold stress}

From each of the nine treatment groups males and females were randomly taken and distributed in five replicates of 10 individuals that were submitted to $-5^{\circ} \mathrm{C}$ for $60 \mathrm{~min}$, using glass vials immersed in a glycol solution cooled by a cryostat (Cryostat Lauda ECO RE 630). After exposure, flies were allowed to recover in $40 \mathrm{~mL}$ food vials under rearing conditions. Survival was assessed by 
counting the number of dead and living individuals in each vial $48 \mathrm{~h}$ after acute cold stress.

\section{Chronic cold stress}

From each of the nine treatment groups males and females were randomly taken and distributed in five replicates of 10 individuals that were submitted to $0{ }^{\circ} \mathrm{C}$ for $24 \mathrm{~h}$, using $40 \mathrm{~mL}$ food vials placed in a cooled-incubator (Model MIR-154-PE; PANASONIC, Healthcare Co., Ltd. Gunma, Japan). After exposure, flies were allowed to recover in $40 \mathrm{~mL}$ food vials under rearing conditions. Survival was assessed by counting the number of dead and living individuals in each vial $48 \mathrm{~h}$ after chronic cold stress.

\section{Critical thermal minimum ( $\left.\mathrm{Ct}_{\text {min }}\right)$}

To estimate the $\mathrm{Ct}_{\min }$ we used a knockdown column consisting of a vertical jacketed glass column $(52 \times 4.7 \mathrm{~cm})$ containing several cleats to help flies not falling out the column while still awake. In order to regulate the temperature, the column was linked to a cryostat (same model as for acute stress assays), and temperature was checked into the column using a thermocouple $\mathrm{K}$ connected to a Comark Tempscan C8600 scanning thermometer (Comark Instruments, Norwich, Norfolk, UK). The thermocouple was inserted at the center of the column, at mid height. Approximately 60 males or females of each conditions were introduced at the top of the column. Flies were allowed to equilibrate in the device at $18^{\circ} \mathrm{C}$ for a few minutes, after which the temperature was decreased to $0{ }^{\circ} \mathrm{C}$ at $0.5^{\circ} \mathrm{C} / \mathrm{min}$. At each fly passing out and falling out of the column the $\mathrm{Ct}_{\min }\left({ }^{\circ} \mathrm{C}\right)$ was recorded. The experiment ended when temperature reached $0{ }^{\circ} \mathrm{C}$.

\section{Chill coma recovery time (CCRT)}

CCRT is defined as the resurgence time of motor activity after a cold knockdown [104]. In order to knockout flies, 40 males and females from each 9 treatments were submitted to $0{ }^{\circ} \mathrm{C}$ for $12 \mathrm{~h}$, using a food vial placed in a cooled-incubator (same model as chronic stress assays). Directly after exposure, flies were rapidly transferred to a $25^{\circ} \mathrm{C}$ regulated room, and spread on a large plane surface using a fine paint brush. Recovery time was individually recorded when a fly was able to stand up. Experimentation ended after $120 \mathrm{~min}$, and non-recovered flies were counted.

\section{Statistical analyses}

Except for CCRT, all analyses of cold tolerance assays were performed using $\mathrm{R}$ (version 3.4.3; $\mathrm{R}$ Core Team, 2016). We modeled survival to $-5^{\circ} \mathrm{C}$ and $0{ }^{\circ} \mathrm{C}$ separately with generalized linear models (GLM) with logistic link function for proportion outcomes (i.e. number of dead/ alive flies per vial). $\mathrm{Ct}_{\min }$ data were analyzed using a
GLM following a Gaussian error family with an identity link function. For these models, response variables were dependent on acclimation duration, sex, and the interaction between these two. We analyzed the effect of each variable through an analysis of deviance ("Anova" function in "car" package, [105]). To facilitate interpretation of GLM effects (from acute and chronic cold stress and $\mathrm{Ct}_{\text {min }}$ data), effect plot function in the package "effects" [106] was used. The effect plots generated show the conditional coefficients ("marginal effects") for all variables and interaction terms, and are available in Additional file 1: Figure S1.

CCRT data were analyzed using survival analysis with the software Prism (version 5.01; GraphPad, La Jolla, CA, USA). We compared each recovery curves using pairwise comparisons (Gehan-Breslow-Wilcoxon Test) for males and females separately. Alpha level of significance for survival analyses was adjusted thanks to Bonferroni correction $(\alpha=0.0013)$.

\section{RNA extraction and sequencing}

Transcriptomic analyses were performed only on females. Three replicates of 15 females from the control group and from the $216 \mathrm{~h}$ (9 day) cold acclimation group were snap-frozen in liquid $\mathrm{N}_{2}$. Samples were ground to a fine powder using pestles in $1.5 \mathrm{~mL}$ Eppendorf tubes immerged in liquid $\mathrm{N}_{2}$. RNA extractions were performed using a Nucleospin Kit (Macherey Nagel, Düren, Germany) following manufacturer's instructions. At the end of the process, total RNA was eluted in $50 \mu \mathrm{L}$ of RNase-free $\mathrm{H}_{2} \mathrm{O}$. For each sample we measured RNA concentrations using a Nanodrop 1000 (Thermo Scientific, Waltham, MA), and estimate integrity using an Agilent Bioanalyzer nanochip (Agilent, Palo Alto, CA). Bioanalyser outputs are shown in Fig. S3. Next-generation RNA sequencing was performed by Eurofins Genomics (Ebersberg, Germany). RNA strand-specific libraries were created using Illumina TruSeq Stranded mRNA Library Preparation Kit (Illumina) according to the manufacturer's instructions. Briefly, polyA-RNA was extracted from total RNA using an oligodT-bead based method. After mRNA fragmentation, first-strand and dUTP-based second strand synthesis was carried out, followed by end-repair, A-tailing, ligation of the indexed Illumina Adapter and digestion of the dUTP-strand. Size selection was done using a bead-based method. After PCR amplification, the resulting fragments were cleaned up, pooled, quantified and used for cluster generation. For sequencing, pooled libraries were loaded on the cBot (Illumina) and cluster generation was performed following manufacturer's instructions. Paired-end sequencing using $125 \mathrm{bp}$ read length was performed on a HiSeq2500 machine (HiSeq Control Software 2.2.58) using HiSeq Flow Cell v4 and TruSeq SBS Kit v4. For processing of raw data RTA 
version 1.18.64 and CASAVA 1.8.4 were used to generate FASTQ-files. RNAseq produced six libraries: three for control and three for cold acclimated females.

\section{Mapping, differential expression analyses, gene ontology term enrichment and protein-protein interactions}

All bioinformatics analyses were performed using Galaxy (https://galaxyproject.org/use/galaxy-genouest/). First, raw data were trimmed using Trimmomatic (version 0.36 [107]), and their quality was checked using FastQC (version 0.11 .2 [108]). Reads were then mapped to $D$. suzukii reference genome [109] using Bowtie2 based Tophat (versions: 2.2.8 and 2.1.1, respectively [110]). The mapping resulted in a mean of $71.11 \%$ mapped reads. Reads were then annotated using reference annotation of D. suzukii [109] and assembled thanks to Cufflinks (version 2.2.1 [111]), and differential expression of transcripts was computed using Cuffdiff (Cuffdiff is part of Cufflinks, version 2.2.1 [111]). We also used two different pipelines for detecting differential expression, edgeR and Deseq2 [112, 113], in order to validate differential expression of transcripts. Very similar outputs of differiential gene expression were found among the three tested pipelines (data not showed). All following analyses were performed on data from Cuffdiff. Transcript expression was considered significantly different between control and cold acclimated flies when the q.value (FDR-adjusted p.value) was $<0.05$. Up and downregulated genes resulting from Cuffdiff were extracted, converted to $D$. melanogaster orthologs, analyzed for GO-terms enrichment using Go-TermFinder [42], and results were reduced and visualized using REVIGO [44]. To ensure validity and robustness of the results, we performed a second analysis in parallel, using the functional enrichment tool in STRING [43]. We used the lists of differential genes (up and down regulated separately) to query STRING database to search for possible protein-protein interactions [43]. The STRING algorithm links proteins (or genes) into networks based on published functional or informatics-predicted interactions [43]. We used the default parameters, with exception regarding the minimum required interaction score, that we increased to 0.9 (high confidence interactions). Disconnected nodes were not displayed in order to increase visibility of the networks.

\section{qPCR}

To validate RNAseq data, we performed $\mathrm{qPCR}$ on selected genes. List of primers are available in Additional file 2: Table S11. For each sample, $500 \mathrm{ng}$ of RNA were reverse transcribed to cDNA using Superscript III first-strand synthesis system (Invitrogen Pty, Thornton, Australia) following manufacturer's instructions. We targeted 11 genes, down- or upregulated, involved in different processes and functions (see Additional file 2: Table S11 for details), including 2 housekeeping genes (RP49 and GAPDH [114, 115]). RP49 showed the most stable expression among the different samples, and was then preferred over GAPDH as reference gene. A Roche LightCycler 480 (Roche, Basel, Switzerland) using SybrGreen I mix (Roche) was used to perform qPCRs, following the protocol described in [92]. Relative gene expressions were calculated using the $\Delta \Delta \mathrm{Ct}$ technique [116]. Expression level of genes resulting from qPCR were then correlated to expression levels resulting from RNAseq using Spearman non-parametric tests and a linear regression in Prism (version 5.01; GraphPad, La Jolla, CA, USA).

\section{Additional files}

\begin{abstract}
Additional file 1: Figure S1. Effect plots from GLMs: impact of acclimation duration on acute or chronic cold stress survival and $\mathrm{Ct}_{\text {min. }}$. The plots show the conditional coefficients ("marginal effects") of all variables included in models as well as effect resulting from the interaction term. The variables are acclimation duration, sex, and their interactions. Figure S2. Chill coma recovery time of control flies at two different age ( 5 and 7 days) and flies acclimated for 9 days. Flies have been submitted to $0^{\circ} \mathrm{C}$ for $12 \mathrm{~h}$, and then their individual time to recover from coma was recorded at $25^{\circ} \mathrm{C}$. Each point corresponds to the recovery time of one fly. Full lines: females, dotted lines: males. Figure S3. Bioanalyser report on RNA extract from Control (COF) and cold acclimated (CAF) samples (females of D. suzukii). Cold acclimation consisted of 5 days old females exposed to $10^{\circ} \mathrm{C}$ during 9 days. (Agilent Bioanalyzer nanochip, Agilent, Palo Alto, CA). (PDF 1085 kb)
\end{abstract}

Additional file 2: Table S1. Differential gene expression from Cuffdiff: Upregulated genes in acclimated flies. Table S2. Differential gene expression from Cuffdiff: Down-regulated genes in acclimated flies. Table S3. Gene ontology term enrichment, Up regulated Cell component. Table S4. Gene ontology term enrichment, Up regulated Molecular function. Table S5. Gene ontology term enrichment, Up regulated Biological process. Table S6. Gene ontology term enrichment, Down regulated Cell component. Table S7. Gene ontology term enrichment, Down regulated Molecular function. Table S8. Gene ontology term enrichment, Down regulated Biological process.

Table S9. Outcomes from STRING enrichment analysis on upregulated genes. Table S10. Outcomes from STRING annotation on down regulated genes. Table S11. List of primers used in qPCR. (XLSX $1022 \mathrm{~kb})$

\section{Abbreviations}

CAF: Cold acclimated females; CCRT: Chill coma recovery time; COF: Control females; $\mathrm{Ct}_{\min }$ : Critical thermal minimum; DD: Degree days; $\mathrm{FC}$ : Fold change; FDR: False discovery rate; GLM: Generalized linear models; GO: Gene ontology; GPCR: G-protein coupled receptor; RNAseq: RNA sequencing

\section{Acknowledgements}

We would like to thanks Sophie MICHON COUDOUEL for Bioanalyser assays, Hélène HENRI who provide primer sequences of RP49 gene, Erwan CORRE who answered our numerous questions about transcriptomic data analysis, and Kevin NOORT for his advices concerning English style.

\section{Funding}

This work has been funded by SUZUKILL project (The French National Research Agency): ANR-15-CE21-0017 and Austrian Science Fund (FWF): I 2604-B25. The funding institutions took no part in the design or implementation of the study nor in the collection, analysis, or interpretation of the data and were not involved in the writing of the manuscript. 


\section{Availability of data and materials}

The data discussed in this publication have been deposited in NCBl's Gene Expression Omnibus [117] and are accessible through GEO Series accession number GSE126708 (https://www.ncbi.nlm.nih.gov/geo/query/acc.cgi?acc= GSE126708)

\section{Authors' contributions}

$\mathrm{TE}$ and $\mathrm{HC}$ designed the experimental plan. TE and HC conduced all experiments. TE analysed the data and performed statistical analysis. TE and HC drafted, reviewed and approved the manuscript.

\section{Ethics approval and consent to participate}

Not applicable.

\section{Consent for publication}

Not applicable.

\section{Competing interests}

The authors declare there are no competing interests.

\section{Publisher's Note}

Springer Nature remains neutral with regard to jurisdictional claims in published maps and institutional affiliations.

Received: 19 February 2019 Accepted: 29 April 2019

Published online: 22 May 2019

\section{References}

1. Asplen MK, Anfora G, Biondi A, Choi D-S, Chu D, Daane KM, et al. Invasion biology of spotted wing Drosophila (Drosophila suzukii): a global perspective and future priorities. J Pest Sci. 2015;88:469-94.

2. Lavrinienko A, Kesäniemi J, Watts PC, Serga S, Pascual M, Mestres F, et al. First record of the invasive pest Drosophila suzukii in Ukraine indicates multiple sources of invasion. J Pest Sci. 2017;90:421-9.

3. Lavagnino NJ, Díaz BM, Cichón LI, De La Vega G, Garrido SA, Lago JD, et al. New records of the invasive pest Drosophila suzukii (Matsumura) (Diptera: Drosophilidae) in the south American continent. Rev Soc Entomológica Argent. 2018;77.

4. Hauser M, Gaimari S, Damus M. Drosophila suzukii new to North America. Fly Times. 2009;43:12-5.

5. Goodhue RE, Bolda M, Farnsworth D, Williams JC, Zalom FG. Spotted wing drosophila infestation of California strawberries and raspberries: economic analysis of potential revenue losses and control costs. Pest Manag Sci. 2011:67:1396-402.

6. Walsh DB, Bolda MP, Goodhue RE, Dreves AJ, Lee J, Bruck DJ, et al. Drosophila suzukii (Diptera: Drosophilidae): invasive pest of ripening soft fruit expanding its geographic range and damage potential. J Integr Pest Manag. 2011;2:G1-7.

7. Kenis M, Tonina L, Eschen R, van der Sluis B, Sancassani M, Mori N, et al. Non-crop plants used as hosts by Drosophila suzukii in Europe. J Pest Sci. 2016;89:735-48.

8. Poyet M, Le Roux V, Gibert P, Meirland A, Prévost G, Eslin P, et al. The wide potential trophic niche of the asiatic fruit fly Drosophila suzukii: the key of its invasion success in temperate Europe? PLoS One. 2015;10:e0142785.

9. Nikolouli K, Colinet H, Renault D, Enriquez T, Mouton L, Gibert P, et al. Sterile insect technique and Wolbachia symbiosis as potential tools for the control of the invasive species Drosophila suzukii. J Pest Sci. 2017:1-15.

10. Hamby KA, Bellamy DE, Chiu JC, Lee JC, Walton VM, Wiman NG, et al. Biotic and abiotic factors impacting development, behavior, phenology, and reproductive biology of Drosophila suzukii. J Pest Sci. 2016;89:605-19.

11. Davidson AM, Jennions M, Nicotra AB. Do invasive species show higher phenotypic plasticity than native species and, if so, is it adaptive? A meta-analysis. Ecol Lett. 2011;14:419-31.

12. Renault D, Laparie M, McCauley SJ, Bonte D. Environmental adaptations, ecological filtering, and dispersal central to insect invasions. Annu Rev Entomol. 2018;63:345-68.

13. Overgaard J, MacMillan HA. The integrative physiology of insect chill tolerance. Annu Rev Physiol. 2017;79:187-208.

14. Dalton DT, Walton VM, Shearer PW, Walsh DB, Caprile J, Isaacs R. Laboratory survival of Drosophila suzukii under simulated winter conditions of the Pacific northwest and seasonal field trapping in five primary regions of small and stone fruit production in the United States. Pest Manag Sci. 2011;67:1368-74.

15. Enriquez T, Colinet H. Basal tolerance to heat and cold exposure of the spotted wing drosophila, Drosophila suzukii. PeerJ. 2017;5:e3112.

16. Kimura MT. Cold and heat tolerance of drosophilid flies with reference to their latitudinal distributions. Oecologia. 2004;140:442-9.

17. Ryan GD, Emiljanowicz L, Wilkinson F, Kornya M, Newman JA. Thermal tolerances of the spotted-wing Drosophila Drosophila suzukii (Diptera: Drosophilidae). J Econ Entomol. 2016;109:746-52.

18. Denlinger DL, Lee RE Jr. Low temperature biology of insects: Cambridge University Press; 2010.

19. MacMillan HA, Sinclair BJ. Mechanisms underlying insect chill-coma. J Insect Physiol. 2011;57:12-20

20. Koštál V. Cell structural modifications in insects at low temperature. In: Denlinger $\mathrm{DL}$, Lee Jr RE, editors. Low temperature biology of insects. 2010. p. 116-140.

21. Foray $V$, Desouhant $E$, Voituron $Y$, Larvor $V$, Renault $D$, Colinet $H$, et al. Does cold tolerance plasticity correlate with the thermal environment and metabolic profiles of a parasitoid wasp? Comp Biochem Physiol A Mol Integr Physiol. 2013;164:77-83.

22. Koštál V, Korbelová J, Rozsypal J, Zahradníčková H, Cimlová J, Tomčala A, et al. Long-term cold acclimation extends survival time at $0^{\circ} \mathrm{C}$ and modifies the metabolomic profiles of the larvae of the fruit fly Drosophila melanogaster. PLoS One. 2011;6:e25025.

23. MacMillan HA, Knee JM, Dennis AB, Udaka H, Marshall KE, Merritt TJS, et al. Cold acclimation wholly reorganizes the Drosophila melanogaster transcriptome and metabolome. Sci Rep. 2016;6:28999.

24. Vesala L, Salminen TS, Koštál V, Zahradníčková H, Hoikkala A. Myo-inositol as a main metabolite in overwintering flies: seasonal metabolomic profiles and cold stress tolerance in a northern drosophilid fly. J Exp Biol. 2012;215:2891-7.

25. Enriquez T, Renault D, Charrier M, Colinet $\mathrm{H}$. Cold acclimation favors metabolic stability in Drosophila suzukii. Front Physiol. 2018;9. https://doi. org/10.3389/fphys.2018.01506.

26. Andersen MK, Folkersen R, MacMillan HA, Overgaard J. Cold acclimation improves chill tolerance in the migratory locust through preservation of ion balance and membrane potential. J Exp Biol. 2017:220:487-96.

27. Colinet $H$, Larvor V, Laparie M, Renault D. Exploring the plastic response to cold acclimation through metabolomics: metabolomics of cold acclimation response. Funct Ecol. 2012;26:711-22.

28. Teets NM, Peyton JT, Ragland GJ, Colinet H, Renault D, Hahn DA, et al. Combined transcriptomic and metabolomic approach uncovers molecular mechanisms of cold tolerance in a temperate flesh fly. Physiol Genomics. 2012:44:764-77

29. Des Marteaux LE, McKinnon AH, Udaka H, Toxopeus J, Sinclair BJ. Effects of cold-acclimation on gene expression in fall field cricket (Gryllus pennsylvanicus) ionoregulatory tissues. BMC Genomics. 2017;18. https://doi. org/10.1186/s12864-017-3711-9.

30. Colinet $\mathrm{H}$, Hoffmann AA. Comparing phenotypic effects and molecular correlates of developmental, gradual and rapid cold acclimation responses in Drosophila melanogaster - Colinet - 2012 - functional ecology - Wiley online library. Funct Ecol. 2012;26:84-93.

31. Koštál V, Vambera J, Bastl J. On the nature of pre-freeze mortality in insects: water balance, ion homeostasis and energy charge in the adults of Pyrrhocoris apterus. J Exp Biol. 2004;207:1509-21.

32. MacMillan HA, Andersen JL, Davies SA, Overgaard J. The capacity to maintain ion and water homeostasis underlies interspecific variation in Drosophila cold tolerance. Sci Rep. 2015;5:18607.

33. Everman ER, Freda PJ, Brown M, Schieferecke AJ, Ragland GJ, Morgan TJ. Ovary development and cold tolerance of the invasive Pest Drosophila suzukii (Matsumura) in the Central Plains of Kansas, United States. Environ Entomol. 2018;47:1013-23.

34. Toxopeus J, Jakobs R, Ferguson LV, Gariepy TD, Sinclair BJ. Reproductive arrest and stress resistance in winter-acclimated Drosophila suzukii. J Insect Physiol. 2016:89:37-51.

35. Jakobs R, Gariepy TD, Sinclair BJ. Adult plasticity of cold tolerance in a continental-temperate population of Drosophila suzukii. J Insect Physiol. 2015;79:1-9.

36. Wallingford AK, Lee JC, Loeb GM. The influence of temperature and photoperiod on the reproductive diapause and cold tolerance of spotted-wing drosophila, Drosophila suzukii. Entomol Exp Appl. 2016;159: $327-37$. 
37. Shearer PW, West JD, Walton VM, Brown PH, Svetec N, Chiu JC. Seasonal cues induce phenotypic plasticity of Drosophila suzukii to enhance winter survival. BMC Ecol. 2016;16:11.

38. Wallingford AK, Loeb GM. Developmental acclimation of Drosophila suzukit (Diptera: Drosophilidae) and its effect on diapause and winter stress tolerance. Environ Entomol. 2016:45:1081-9.

39. Stockton D, Wallingford A, Loeb G. Phenotypic plasticity promotes overwintering survival in a globally invasive crop Pest, Drosophila suzukii. Insects. 2018;9:105

40. Tochen S, Dalton DT, Wiman N, Hamm C, Shearer PW, Walton VM. Temperature-related development and population parameters for Drosophila suzukii (Diptera: Drosophilidae) on Cherry and blueberry. Environ Entomol. 2014:43:501-10.

41. Hong G, Zhang W, Li H, Shen X, Guo Z. Separate enrichment analysis of pathways for up- and downregulated genes. J R Soc Interface. 2014;11. https://doi.org/10.1098/rsif.2013.0950.

42. Boyle El, Weng S, Gollub J, Jin H, Botstein D, Cherry JM, et al. GO: TermFinder--open source software for accessing gene ontology information and finding significantly enriched gene ontology terms associated with a list of genes. Bioinforma Oxf Engl. 2004;20:3710-5.

43. Szklarczyk D, Franceschini A, Wyder S, Forslund K, Heller D, Huerta-Cepas J, et al. STRING v10: protein-protein interaction networks, integrated over the tree of life. Nucleic Acids Res. 2015;43 Database issue:D447-52.

44. Supek F, Bošnjak M, Škunca N, Šmuc T. REVIGO summarizes and visualizes long lists of gene ontology terms. PLoS One. 2011;6:e21800.

45. Dalman MR, Deeter A, Nimishakavi G, Duan Z-H. Fold change and p-value cutoffs significantly alter microarray interpretations. BMC Bioinformatics. 2012;13:S11

46. Teets NM, Denlinger DL. Physiological mechanisms of seasonal and rapid cold-hardening in insects. Physiol Entomol. 2013;38:105-16.

47. Smith LB. Effects of cold-acclimation on supercooling and survival of the rusty grain beetle, Cryptolestes ferrugineus (Stephens) (Coleoptera: Cucujidae), at subzero temperatures. Can J Zool. 1970;48:853-8.

48. Waagner D, Holmstrup M, Bayley M, Sørensen JG. Induced cold tolerance mechanisms depend on duration of acclimation in the chill sensitive Folsomia candida (Collembola). J Exp Biol. 2013:jeb.079814.

49. Chen J, Nolte $V$, Schlötterer C. Temperature-related reaction norms of gene expression: regulatory architecture and functional implications. Mol Biol Evol. 2015;32:2393-402.

50. Gerken AR, Eller OC, Hahn DA, Morgan TJ. Constraints, independence, and evolution of thermal plasticity: probing genetic architecture of long- and short-term thermal acclimation. Proc Natl Acad Sci. 2015:201503456.

51. Parker DJ, Vesala L, Ritchie MG, Laiho A, Hoikkala A, Kankare M. How consistent are the transcriptome changes associated with cold acclimation in two species of the Drosophila virilis group? Heredity. 2015;115:13-21.

52. Hazel JR. Cold adaptation in ectotherms: regulation of membrane function and cellular metabolism. In: Wang LCH, editor. Animal adaptation to cold. Berlin, Heidelberg: Springer Berlin Heidelberg; 1989. p. 1-50

53. Hazel JR. Thermal adaptation in biological membranes: is homeoviscous adaptation the explanation? Annu Rev Physiol. 1995:57:19-42.

54. Cossins AR. Temperature adaptation of biological membranes: Portland Press; 1994.

55. Illsley NP, Lin HY, Verkman AS. Lipid domain structure correlated with membrane protein function in placental microvillus vesicles. Biochemistry. 1987;26:446-54

56. Zachariassen KE, Kristiansen E, Pedersen SA. Inorganic ions in cold-hardiness. Cryobiology. 2004;48:126-33.

57. Koštál V, Yanagimoto M, Bastl J. Chilling-injury and disturbance of ion homeostasis in the coxal muscle of the tropical cockroach (Nauphoeta cinerea). Comp Biochem Physiol B Biochem Mol Biol. 2006;143:171-9.

58. MacMillan HA, Williams CM, Staples JF, Sinclair BJ. Reestablishment of ion homeostasis during chill-coma recovery in the cricket Gryllus pennsylvanicus. Proc Natl Acad Sci. 2012;109:20750-5

59. MacMillan HA, Sinclair BJ. The role of the gut in insect chilling injury: coldinduced disruption of osmoregulation in the fall field cricket, Gryllus pennsylvanicus. J Exp Biol. 2011;214(Pt 5):726-34.

60. MacMillan HA, Findsen A, Pedersen TH, Overgaard J. Cold-induced depolarization of insect muscle: differing roles of extracellular K+ during acute and chronic chilling. J Exp Biol. 2014:jeb.107516.
61. Hosler JS, Burns JE, Esch HE. Flight muscle resting potential and speciesspecific differences in chill-coma. J Insect Physiol. 2000;46:621-7.

62. Andersen JL, MacMillan HA, Overgaard J. Muscle membrane potential and insect chill coma. J Exp Biol. 2015;218(Pt 16):2492-5.

63. Kelty JD, Killian KA, Lee RE. Cold shock and rapid cold-hardening of pharate adult flesh flies (Sarcophaga crassipalpis): effects on behaviour and neuromuscular function following eclosion. Physiol Entomol. 1996;21:283-8.

64. Armstrong GAB, Rodríguez EC, Meldrum Robertson R. Cold hardening modulates $\mathrm{K}+$ homeostasis in the brain of Drosophila melanogaster during chill coma. J Insect Physiol. 2012;58:1511-6.

65. Rodgers $\mathrm{Cl}$, Armstrong GAB, Robertson RM. Coma in response to environmental stress in the locust: a model for cortical spreading depression. J Insect Physiol. 2010;56:980-90.

66. Rodgers Cl, Armstrong GAB, Shoemaker KL, LaBrie JD, Moyes CD, Robertson RM. Stress preconditioning of spreading depression in the locust CNS. PLoS One. 2007;2:e1366.

67. Robertson RM. Thermal stress and neural function: adaptive mechanisms in insect model systems. J Therm Biol. 2004;29:351-8.

68. Coello Alvarado LE, MacMillan HA, Sinclair BJ. Chill-tolerant Gryllus crickets maintain ion balance at low temperatures. J Insect Physiol. 2015;77:15-25.

69. MacMillan HA, Ferguson LV, Nicolai A, Donini A, Staples JF, Sinclair BJ. Parallel ionoregulatory adjustments underlie phenotypic plasticity and evolution of Drosophila cold tolerance. J Exp Biol. 2015;218:423-32.

70. Grumiaux C, Andersen MK, Colinet H, Overgaard J. Fluctuating thermal regime preserves physiological homeostasis and reproductive capacity in Drosophila suzukii. J Insect Physiol. 2019. https://doi.org/10.1016/j.jinsphys. 2019.01.001.

71. Frolov RV, Singh S. Temperature and functional plasticity of L-type Ca2+ channels in Drosophila. Cell Calcium. 2013;54:287-94.

72. Findsen A, Overgaard J, Pedersen TH. Reduced L-type Ca2+ current and compromised excitability induce loss of skeletal muscle function during acute cooling in locust. J Exp Biol. 2016:jeb.137604

73. Rohrbough J, Broadie K. Lipid regulation of the synaptic vesicle cycle. Nat Rev Neurosci. 2005:6:139-50.

74. Salminen TS, Vesala L, Laiho A, Merisalo M, Hoikkala A, Kankare M. Seasonal gene expression kinetics between diapause phases in Drosophila virilis group species and overwintering differences between diapausing and nondiapausing females. Sci Rep. 2015;5:11197.

75. Königer A, Grath S. Transcriptome analysis reveals candidate genes for cold tolerance in Drosophila ananassae. Genes. 2018:9:624.

76. Lin Y. Extended life-span and stress resistance in the Drosophila mutant methuselah. Science. 1998;282:943-6.

77. Simon M, Strathmann M, Gautam N. Diversity of $G$ proteins in signal transduction. Science. 1991;252:802-8.

78. Pfister TD, Storey KB. Insect freeze tolerance: roles of protein phosphatases and protein kinase a. Insect Biochem Mol Biol. 2006;36:18-24.

79. Fujiwara $Y$, Denlinger DL. p38 MAPK is a likely component of the signal transduction pathway triggering rapid cold hardening in the flesh fly Sarcophaga crassipalpis. J Exp Biol. 2007:210:3295-300.

80. Stronach BE, Perrimon N. Stress signaling in Drosophila. Oncogene. 1999;18:6172-82.

81. Johnson GL. Mitogen-activated protein kinase pathways mediated by ERK, JNK, and p38 protein kinases. Science. 2002;298:1911-2.

82. Dascal N. Signalling via the G protein-activated K+ channels. Cell Signal. 1997;9:551-73

83. Bharucha KN, Tarr P, Zipursky SL. A glucagon-like endocrine pathway in Drosophila modulates both lipid and carbohydrate homeostasis. J Exp Biol. 2008;211:3103-10.

84. Musselman LP, Fink JL, Ramachandran PV, Patterson BW, Okunade AL, Maier $E$, et al. Role of fat body lipogenesis in protection against the effects of caloric overload in Drosophila. J Biol Chem. 2013:jbc-M112.

85. Kayukawa T, Chen B, Hoshizaki S, Ishikawa Y. Upregulation of a desaturase is associated with the enhancement of cold hardiness in the onion maggot, Delia antiqua. Insect Biochem Mol Biol. 2007:37:1160-7.

86. Greenberg AJ, Moran JR, Coyne JA, Wu C-I. Ecological adaptation during incipient speciation revealed by precise gene replacement. Science. 2003;302:1754-7.

87. Kankare M, Parker DJ, Merisalo M, Salminen TS, Hoikkala A. Transcriptional differences between diapausing and non-diapausing D. montana females reared under the same photoperiod and temperature. PLoS One. 2016;11:e0161852 
88. Vesala L, Salminen TS, Laiho A, Hoikkala A, Kankare M. Cold tolerance and cold-induced modulation of gene expression in two Drosophila virilis group species with different distributions: cold-induced changes in gene expression. Insect Mol Biol. 2012;21:107-18.

89. Colinet H, Overgaard J, Com E, Sørensen JG. Proteomic profiling of thermal acclimation in Drosophila melanogaster. Insect Biochem Mol Biol. 2013:43:352-65

90. Overgaard J, Malmendal A, Sørensen JG, Bundy JG, Loeschcke V, Nielsen NC, et al. Metabolomic profiling of rapid cold hardening and cold shock in Drosophila melanogaster. J Insect Physiol. 2007;53:1218-32.

91. Overgaard J, Sørensen JG, Com E, Colinet H. The rapid cold hardening response of Drosophila melanogaster: complex regulation across different levels of biological organization. J Insect Physiol. 2014;62:46-53.

92. Colinet H, Lee SF, Hoffmann A. Temporal expression of heat shock genes during cold stress and recovery from chill coma in adult Drosophila melanogaster: heat shock response to cold stress. FEBS J. 2010;277:174-85.

93. Richter K, Haslbeck M, Buchner J. The heat shock response: life on the verge of death. Mol Cell. 2010;40:253-66.

94. Ekengren S, Hultmark D. A family of Turandot-related genes in the humoral stress response of Drosophila. Biochem Biophys Res Commun. 2001;284:998-1003.

95. Ekengren S, Tryselius Y, Dushay MS, Liu G, Steiner H, Hultmark D. A humoral stress response in Drosophila. Curr Biol. 2001;11:714-8.

96. Zhang J, Marshall KE, Westwood JT, Clark MS, Sinclair BJ. Divergent transcriptomic responses to repeated and single cold exposures in Drosophila melanogaster. J Exp Biol. 2011;214:4021-9.

97. Hoffmann AA. Physiological climatic limits in : patterns and implications. J Exp Biol. 2010;213:870-80.

98. Klepsatel P, Gáliková M, De Maio N, Huber CD, Schlötterer C, Flatt T. Variation in thermal performance and reaction norms among populations of Drosophila melanogaster. Evolution. 2013;67:3573-87.

99. Mensch J, Hurtado J, Zermoglio PF, de la Vega G, Rolandi C, Schilman PE, et al. Enhanced fertility and chill tolerance after cold-induced reproductive arrest in females of temperate species of the Drosophila buzzatii complex. J Exp Biol. 2017;220(Pt 4):713-21.

100. Baker DA, Russell S. Gene expression during Drosophila melanogaster egg development before and after reproductive diapause. BMC Genomics. 2009;10:242

101. Lirakis M, Dolezal M, Schlötterer C. Redefining reproductive dormancy in Drosophila as a general stress response to cold temperatures. J Insect Physiol. 2018;107:175-85.

102. Dyck VA, Hendrichs J, Robinson AS, editors. Sterile insect technique: principles and practice in area-wide integrated pest management. Dordrecht: Netherlands: Springer; 2005.

103. Colinet H, Renault D. Metabolic effects of CO2 anaesthesia in Drosophila melanogaster. Biol Lett. 2012;8:1050-4.

104. David RJ, Gibert P, Pla E, Petavy G, Karan D, Moreteau B. Cold stress tolerance in Drosophila: analysis of chill coma recovery in D. melanogaster. J Therm Biol. 1998;23:291-9.

105. Fox J, Weisberg S, An R. Companion to applied regression. 2nd ed. Thousand Oaks: Sage; 2011.

106. Fox J. Effect displays in $\mathrm{R}$ for generalised linear models. J Stat Softw. 2003;8:1-27.

107. Bolger AM, Lohse M, Usadel B. Trimmomatic: a flexible trimmer for Illumina sequence data. Bioinforma Oxf Engl. 2014:30:2114-20.

108. Andrew S. FastQC a quality control tool for high throughput sequence data. Babraham Bioinformatics. 2010; http://www.bioinformatics.babraham.ac.uk/ projects/fastqc/.

109. Chiu JC, Jiang X, Zhao L, Hamm CA, Cridland JM, Saelao P, et al. Genome of Drosophila suzukii, the spotted wing Drosophila. G3 GenesGenomesGenetics. 2013;3:2257-71.

110. Kim D, Pertea G, Trapnell C, Pimentel H, Kelley R, Salzberg SL. TopHat2 accurate alignment of transcriptomes in the presence of insertions, deletions and gene fusions. Genome Biol. 2013;14:R36.

111. Trapnell C, Williams BA, Pertea G, Mortazavi A, Kwan G, van Baren MJ, et al. Transcript assembly and abundance estimation from RNA-Seq reveals thousands of new transcripts and switching among isoforms. Nat Biotechnol. 2010;28:511-5.

112. Robinson MD, McCarthy DJ, Smyth GK. edgeR: a Bioconductor package for differential expression analysis of digital gene expression data. Bioinformatics. 2010;26:139-40.
113. Love MI, Huber W, Anders S. Moderated estimation of fold change and dispersion for RNA-seq data with DESeq2. Genome Biol. 2014;15:550.

114. Monnin D, Kremer N, Berny C, Henri H, Dumet A, Voituron Y, et al. Influence of oxidative homeostasis on bacterial density and cost of infection in Drosophila-Wolbachia symbioses. J Evol Biol. 2016;29:1211-22.

115. Zhai Y, Lin Q, Zhou X, Zhang X, Liu T, Yu Y. Identification and validation of reference genes for quantitative real-time PCR in Drosophila suzukii (Diptera: Drosophilidae). PLoS One. 2014;9:e106800.

116. Pfaffl MW. A new mathematical model for relative quantification in real-time RT-PCR. Nucleic Acids Res 2001;29:e45-e45.

117. Edgar R, Domrachev M, Lash AE. Gene expression omnibus: NCBI gene expression and hybridization array data repository. Nucleic Acids Res. 2002;30:207-10.

\section{Ready to submit your research? Choose BMC and benefit from:}

- fast, convenient online submission

- thorough peer review by experienced researchers in your field

- rapid publication on acceptance

- support for research data, including large and complex data types

- gold Open Access which fosters wider collaboration and increased citations

- maximum visibility for your research: over $100 \mathrm{M}$ website views per year

At BMC, research is always in progress.

Learn more biomedcentral.com/submissions 